This material may be downloaded for personal use only. Any other use requires prior permission of the American Society of Civil Engineers. This material may be found at Huynh MT, Pham CH, Rogers CA, Hancock GJ (2021) "Structural behavior of screwed connections in coldformed steel beams", ASCE Journal of Structural Engineering 147(3): 04020354. https://doi.org/10.1061/(ASCE)ST.1943-541X.0002937

\title{
Structural Behavior of Screwed Connections in Cold-Formed Steel Beams
}

\author{
Minh Toan Huynh', Cao Hung Pham ${ }^{2, *}$, Colin A. Rogers ${ }^{3}$ and Gregory J Hancock ${ }^{4}$ \\ ${ }^{1}$ Doctoral Candidate, School of Civil Engineering, The University of Sydney, NSW 2006, Australia. \\ Emails: minhtoan.huynh@sydney.edu.au \\ 2 Senior Lecturer, School of Civil Engineering, The University of Sydney, NSW 2006, Australia \\ Email: caohung.pham@sydney.edu.au \\ ${ }^{3}$ Professor, Department of Civil Engineering and Applied Mechanics, McGill Univ., Montreal, QC, Canada. Email: \\ colin.rogers@mcgill.ca \\ ${ }^{4}$ Emeritus Professor and Professorial Research Fellow, School of Civil Engineering, The University of Sydney, \\ NSW 2006, Australia \\ Email: gregory.hancock@sydney.edu.au
}

Keywords: Cold-formed steel; Screws; Screwed connections; Angle cleat.

\begin{abstract}
Two test series were carried out on angle cleat connections between cold-formed channels as beams and rectangular hollow sections as support members. The objective of the tests was to determine the effect of connection rotation from the beam on the shear capacity of the connection. Self-drilling screws were used to attach the channels to the angle cleats with the failure limit states always occurring in this part of the connection. A dual actuator test apparatus which could apply controlled displacement and rotation to the beams was used. The specimens contained different thicknesses of the channels, which allowed for two limit states involving failure modes of the screws fracturing in shear and bearing and tilting failure of the screws in the channel sheet material. The experimental results show the effect of rotation on reducing the shear capacity of the screwed connections. An analytical model for the connection is developed using the relation between the bearing force and deformation of the individual screw connections.
\end{abstract}

\section{Introduction}

Cold-formed steel structural members are being used commonly in construction of steel framed housing, light-weight portal frames, roof systems and wall systems due to their light weight and ease of construction. In recent years cold-formed steel has begun to be adopted in construction of mid-rise residential and commercial buildings in the form of hybrid light steel panel and modular systems. The increasing demand on steel structures in the form of modular systems requires research and development into new types of connections besides the conventional connections of hot-rolled to hot-rolled and cold-formed to cold-formed steel members. Modular construction 
usually uses 2D-panels and 3D-modules, which consist entirely of thin steel members. In these systems, vertical loads are transferred through walls or corner and intermediate posts. However, for medium-rise buildings, a podium structure or skeletal structure is required for supporting the load from the above modules (Lawson and Ogden 2008). In these 'hybrid' modular systems, the primary steel frames consist of hot-rolled I-sections or tubular sections, while the wall and floor systems are made of cold-formed steel. For attaching cold-formed C-sections to an I-beam, extended cleat plates need to be used (1b). This could lead to potential lateral instability as well as overstressing due to bending. Coping the top flanges of the secondary beam to allow their webs to be placed closer to the main beam is a common practice with hot-rolled steel construction (Fig. 1a). However, this is not easily achievable with cold-formed steel beams because of their slender nature; moreover the cold-formed steel sections often require that both flanges and web remain intact to achieve full bending and shear capacity and to maintain stability of the member.

A possible solution is to use a rectangular hollow section as the primary beam, and to connect the cold-formed steel beam using an angle cleat / web side plate (Fig. 2a). This allows for simple and effective angle cleat design. Similarly, the main columns can also be designed as hollow sections (Fig. 2b). However, these configurations have not been properly investigated and there is little research on these types of connections. Designers often have to rely on independent testing or calculation because no behavioural and design models have been developed. Many of these connections are usually regarded as simple connections although they can demonstrate semi-rigid behaviour. Furthermore, strength design generally involves combining statically the strength of the connectors without considering the deformation of each element. When the limit states associated with bearing or shear fracture, the elastic deformation of the connections may greatly affect their capacity. Consequently, it is of interest to study and investigate the behaviour of the connections from cold-formed steel beams to hollow steel sections, and to develop an approach in building design models for such connections.

For connection experiments using only one actuator, the ratio between moment and shear force transferred to the connection is a fixed number, which depends on the distance to the actuator. A method for testing beam-to-column simple connections was proposed by Astaneh-Asl (1989). It includes two actuators controlling shear force and moment independently. Similar test setups have been used by Rogers et al. (2016) at McGill University and Thomas et al. (2017) for hot-rolled 
steel connections. The advantage of this testing configuration is that any pre-defined ratios of moment and shear force can be applied to the connection.

All of the shear connection tests in hot-rolled steels using dual-actuator test rigs have shown the importance of rotation in connection design. However, a similar method has not been developed for cold-formed steel connections. For connections working under shear force or moment, designers often have to rely on independent testing and FE modelling, or using the established design procedure for hot-rolled steel connections (Hogan 2007). There have been a few attempts to provide design methods for angle cleats. Research reports by Fox $(2003,2005)$ showed the effect of clip angles acting as bearing stiffeners on cold-formed steel floor assemblies. Yu et al. (2016) studied the behaviour and strength of clip angles under shear load and proposed two design methods for shear strength of clip angles with and without consideration of the clip deformation. Due to their slenderness, these angle clips only reached peak loads after a large amount of deformation, and subsequently failed in local buckling or distortional buckling (Yu et al. 2016).

This paper describes connection experiments carried out using a dual-actuator test set-up in the J.W. Roderick Laboratory for Materials and Structures at the University of Sydney. The experiments involved a cold-formed steel channel connected to a rectangular hollow steel section (RHS) using an angle cleat. One flange of the angle cleat was attached to the channel by two screws whilst the other flange was fixed to the beam using four bolts. The set-up used two actuators connected to the channel; the speeds of the two actuators were pre-defined and varied for each test. Therefore, different amounts of moment and shear could be transferred to the connection for each test. Two test series were carried out, which were associated with two distinct limit states: Series 1 involved shear fracture of the screws and Series 2 involved bearing/tilting failure of the screws. The thickness of the channel was the main governing factor in determining the required limit state. The paper then describes the development of an analytical model to predict the effect of rotation on the shear capacity of a connection which works with different types of failure in the screws. 


\section{Laboratory Test Program}

\subsection{Test Configuration and Specimens}

A typical floor beam will have rotation and shear at both ends depending on its span and the stiffness of its connections. The aim of the tests is to apply a realistic shear force, moment and rotation on the connection. This can be achieved by using two actuators on a single cantilever beam: where one actuator (A) mainly controls the shear force and the other (B) mainly controls the rotation of the beam.

Fig. 3 shows a schematic diagram of a specimen and the corresponding moment and shear force diagrams. The C200 beam was connected to a rectangular hollow section RHS250x150x9 via an angle cleat (equal angle $40 \mathrm{~mm}$ x $40 \mathrm{~mm}$ x $4 \mathrm{~mm}$ ). The angle cleat (Fig. 4) was bolted to the RHS by 4 high strength M12 bolts to AS/NZS 1252.1:2016 (Australian/New Zealand Standard 2016), which was itself bolted firmly to the existing stocky columns forming the rig. In these experiments, only two screw connectors were used: G14-10TPI self-drilling screws (6.3 mm diameter of the threads and 10 threads per inch along the screw's rotational axis). This configuration allowed the loads to be transferred evenly to each screw, which made the system statically determinate if the vertical forces on the top and bottom screws are assumed equal.

Shear force $\left(F_{\mathrm{c}}\right)$ and moment $\left(M_{\mathrm{c}}\right)$ acting on the connection can be calculated from the actuator forces and distances from the actuators to the connection as follows:

$$
\begin{gathered}
F_{C}=F_{A}+F_{B} \\
M_{C}=0.2 F_{A}+0.78 F_{B}
\end{gathered}
$$

The test rig (illustrated in Fig. 4) was built on an existing frame in the J.W. Roderick Structures Laboratory in the School of Civil Engineering, the University of Sydney. The frame consists of four universal columns supporting two hanging universal beams at the top (Fig. 5). Two MTS actuators were suspended from $32 \mathrm{~mm}$ - thick plates which were attached to the universal beams. Each hydraulic actuator could exercise a maximum force of $253 \mathrm{kN}$ in compression and $162 \mathrm{kN}$ in tension. The actuators, controlled concurrently by an MTS FlexTest Controller, were capable of displacing up to $500 \mathrm{~mm}$. The ends of each actuator were attached to rotary ball-joints so that they could follow the movement of the channel without restraint. 
Fig. 4 shows the test setup with the columns which hold the RHS removed to reveal the T-plates (orange), the loading system (yellow) from the hydraulic jacks to the channel and the restraining system (red) connecting from the loading plates to the four outer rails (blue). The holes on the flanges of the T-plates are slotted-holes to allow different horizontal positions of the RHS (as shown in Fig. 4 and later in Fig. 8b). Similarly, the slots on the webs of the top T-plates allow for different size RHS with various heights (Fig. 4).

Fig. 5 shows the test setup in the J.W. Roderick Lab. There is a steel base under the specimen where the measurement instruments were placed. Before each test, the position of the specimen was checked to be at the middle of the frame and its orientation was checked to have the web vertically aligned. The horizontal position of the specimen could be changed by adjusting the RHS with the slotted holes (as shown later in Fig. 8b). The vertical orientation of the channel could be adjusted by changing lengths of the turnbuckles in the restraining system.

The test program included two test series. They incorporated different thicknesses of the channels to capture two distinct failure modes of the screws:

- Series 1: C20024 - 2.4 mm thickness - screws fail in shear,

- Series 2: SC20012 - 1.2 mm thickness - bearing and tilting failure of the screw connection.

A SupaCee section was used in Series 2 because channels with $200 \mathrm{~mm}$ depth and $1.2 \mathrm{~mm}$ thickness are only available in that form (BlueScope Steel Limited 2014). Moreover, a thicker section would result in fracture of the screw, which is contradictory to the purpose of this test series. Two types of C-sections were used. These are a simple lipped channel C20024 (2.4 mm thickness - G450 steel to AS 1397-1993 (Australian Standard 1993)) and a SupaCee lipped channel SC20012 (1.2 mm thickness - G500 steel to AS 1397-1993 (Australian Standard 1993)). Measured material properties are shown in Table 1.

A water jet cutter was used to cut the holes in the channels. There are four rows of $13 \mathrm{~mm}$ diameter holes which were used for attaching the channel to the loading plates (Fig. 6) using M12 bolts. For the SC20012 members, due to the slenderness of the section (1.2 mm thickness) and the high concentration of shear force between the angle cleat and Actuator A (Fig. 3), local buckling could occur in this segment of the members. Therefore, two equal angles were bolted to each channel acting as stiffeners (Fig. 6). Two additional rows of $7 \mathrm{~mm}$ holes were cut in the SC20012 
members. M6 bolts were used to attach the stiffeners to the channels. Fig. 6 shows an SC20012 specimen with the stiffeners and various brackets along its length, which were used to place different measurement instruments (inclinometers and transducers).

The distance between the two self-drilling screws was chosen to maximise the moment capacity of the connection, which was as large as possible without compromising the capacity of the screws. Hence for Series 1, D was chosen to be $160 \mathrm{~mm}$, which was the largest flat space in the web without the influence of the rounded corners. For Series 2, to avoid the longitudinal web stiffeners in the SC20012 section, the distance between the two screws was set at $115 \mathrm{~mm}$ (Fig. 7).

When the specimens were prepared for Series 1, the screws were installed from the angle cleat to the channel as it was inaccessible from the channel side. The distance between the 2 screws was chosen to be as large as possible, their positions were close to the flanges of the channel, hence the clipped flanges prevented the electric screwdriver being placed perpendicular to the web surface (as can be seen in Fig. 7). For Series 1, as the limit state was fracture of the screws and there was little deformation in the sheet steels, the orientation of the screws was unimportant. However, for Series 2, bearing and tilting failure was required. As mentioned in a previous paper by Huynh et al. (2018a), for the bearing and tilting limit state, a connection with the screws installed from a thin sheet to a thicker sheet usually has more strength compared to a connection with the screws installed from a thick sheet. Furthermore, the latter connection may also involve pull-out failure, which was undesirable in these experiments. Hence in Series 2, the screws were installed from the thin channel to the angle cleat. In summary:

- Series 1: $D=160 \mathrm{~mm}$, screws installed from angle cleat to channel,

- Series 2: $D=115 \mathrm{~mm}$, screws installed from channel to angle cleat.

\subsection{Restraining System}

As the loading plates did not pass through the shear centre of the C-section, there could be a twisting moment acting on the beam. In order to keep the web of the beam vertical, a restraining system was installed (Fig. 8). The design of this lateral bracing system was inspired by research conducted by Yarimci et al. (1967).

The restraining system included length-adjustable beams: two threaded rods each connected by a turnbuckle at the middle. One end of each rod connected to the outer rails (blue in Fig. 8b). The 
other end connected to rotatable plates (yellow plates on top and bottom of each loading plates) so that the web of the beam was always vertical during its downward motion. The horizontal position of the rod could be changed along the rails and their length could be adjusted by rotating the turnbuckles. The two ends of each rod were swivel ball joint bearings (Fig. 8a) which allowed for the rotation which occurred in the experiments when the channel was moving down. Consequently, the rods with turnbuckles balanced out the twisting moment so that the beam only experienced a vertical shear force and moment about the major axis.

\subsection{Instrumentation}

Linear variable displacement transducers (LVDTs) were used to track the displacement of the channel and the connection (Fig. 9). At the connection position, LVDTs were used at the front (on the angle cleat) and the back (on the channel) to track the possible bearing displacements of the screws. Measurements of vertical displacement of the channel were taken on the flange and the lower web to avoid errors from any possible twisting of it. Four inclinometers were attached on the web and the top flange to track the in-plane rotation of the channel (Fig. 9). An LVDT could not be placed under Inclinometer I1 due to the small space between the angle cleat and Actuator A which was occupied by the rotating plates of the restraining system (Fig. 8c). Another inclinometer was attached to the RHS to measure any twisting of the hollow section.

The two servo actuators in the test rig were controlled via an MTS FlexTest Controller. Displacement control was applied through the interface of the MultiPurpose TestWare (MPT) software by setting the speed of each actuator. The MPT application also displayed and recorded forces and displacements of the actuators over time.

All of the measurement instruments were connected to a DataLogger and calibrated using the Vishay System 5000 StrainSmart software. Another DataLogger received signals from the MTS FlexTest Controller for reading the two actuators' loads and displacements. The measurement instruments were connected to Vishay Model 5100B scanners that were used to record data at 1 scan/s. Furthermore, digital image correlation (DIC) was also used to track displacement and rotation at the back of the beam where Inclinometer I1 was located. A description of the DIC method can be found in the doctoral thesis by Huynh (2019). The data from DIC method and MPT software could be used for comparison and verification against the data from the LVDTs and inclinometers. 


\subsection{Test Program}

Displacement control was used to command the actuators in the experiments. Each actuator could move with a predetermined rate, which could be changed during the experiments. Initially, the actuators were moved downward at the same speed until slack was removed (i.e. the system got past the slip stage in the connections and forces were perceptible). Then the rate of Actuator B would be increased to produce rotation on the test specimen. The two actuators were operated so that the ratio of their running rates was a fixed number in this stage. The ratio of speed of Actuator B over the speed of Actuator A in this phase was called the Running Ratio $(R R)$.

In each series, there were a total of 15 tests carried out with three identical tests for each Running Ratio $(R R)$, which was chosen as 1.00, 1.75, 2.50, 2.875 and 3.25. When the thickness of the angle cleat and the channel (C20024) was fixed at $4.0 \mathrm{~mm}$ and $2.4 \mathrm{~mm}$ respectively in Series 1 , the bearing capacity of the screw connections was larger than the shear capacity of the screws. Therefore the screws failed in shear and controlled the failure of each experiment. The experiment was stopped when there were one or two screws fractured in shear.

When the thicknesses of the angle cleat and the channel (SC20012) were fixed at $4.0 \mathrm{~mm}$ and $1.2 \mathrm{~mm}$ respectively in Series 2, the bearing and tilting strength was higher than or equal to the shear capacity of the screws. Hence there were large deformations in the connections before failure. Each experiment was stopped when one end of the channels was about to contact the RHS beam. For the tests with high Running Ratios (2.50, 2.875 and 3.25), the channel could reach the RHS before failure occurred. Therefore, one packing plate (with a thickness of $4 \mathrm{~mm}$ ) was placed between the angle cleat and the RHS to allow for a larger rotation of the channel (Fig. 9b).

\section{Experimental Results}

\subsection{Interpretation of Experimental Results}

The results of the two test series are presented herein to provide consistent and logical experimental results, the following assumptions need to be used during the interpretation of the data:

- $\quad$ The main aim of the experiments was to investigate the relationship between the rotation and shear capacity of each connection. In each test, there was a moment induced by the rotation 
which caused the shear capacity to drop at higher rotations. This moment was small when compared with the moment capacity of the channel and so channel failure did not occur.

- Displacement control was used for both actuators. The ratio between the speeds of Actuator B over Actuator A was fixed throughout each experiment (Running Ratio). This running ratio acted as a means to provide shear and rotation to the connection. Due to slippage between the load plates, the channel and the bolts, actual rotations cannot be calculated directly from the displacements of the actuators. The rotation of the channel at the connection was measured using the inclinometer that was closest to the connection (Inclinometer 1), Digital Image Correlation (DIC) and other inclinometers along the channel were also used for comparison.

- $\quad$ The lateral restraining system kept the channel vertical throughout each experiment. Therefore the amount of twisting involved was negligible.

- $\quad$ The angle cleats were rigidly bolted to the RHS and the connection flexibility was due to elastic deformation of the angle cleat alone.

- $\quad$ The failure mode in the Series 2 experiments was generally screws bearing failure in the web of the channel (i.e. the hole elongated and material piled up in front of the screws). There was also considerable tilting of the screws. In several tests, the bearing force exceeded the shear capacity of the screws which led to their fracture. For the tests with high Running Ratios, a large amount of rotation was introduced, which generated a slightly curved bearing path in the screwed connections. Consequently, the piled up material was redistributed around the screws' perimeters, so that the amount of materials in front of the screws at any given time was smaller, which produced a long plateau in the shear versus rotation curve. The data for the shear capacity versus rotation of the connection were constructed based on these observed behaviour:

- $\quad$ For the tests which ended up with fracture of the screws (Series 1 and a number of tests from Series 2), the shear and rotation were taken just before the failure (Fig. 10a).

- $\quad$ For the test which involved bearing failure only, there was no distinct indication of a failure. Therefore the shear and rotation were taken when the shear load decreased by an amount of $10 \%$ from the peak load or the second peak in shear (Fig. 10b).

\subsection{Series 1: Fracture of the Screws}

In all of the tests in Series 1, the force from Actuator A acted downwards (positive) and Actuator B acted upwards (negative). Initially, the forces increased gradually as slip occurred in the bolt 
groups. After settlement, the loads rose continuously up to the peak values. There was a small plastic region in all tests of the series which developed just before failure. As the failure mechanism involved screws failing in shear, the failure was sudden: the load immediately dropped to zero (in cases where two screws failed at the same time) or halved (in the case where one screw failed first). Fig. 11 shows typical load - displacement curves from the two actuators. From the loads in the two actuators, shear and moment at the connection can be calculated. Two examples are shown in Fig. 12. In the case of (a) with an $R R$ of 1.0, the restraining moment was negative indicating an applied moment as discussed later. In the case of (b) with an $R R$ of 2.5, the restraining moment was positive as expected.

In order to calculate the bearing force on the screws, it is assumed that the vertical force transfers equally to each screw. Hence the vertical and horizontal forces acting on each screw can by calculated by:

$$
\begin{gathered}
V_{v}=F_{c} / 2 \\
V_{h}=M_{c} / D
\end{gathered}
$$

where $F_{\mathrm{c}}$ is the vertical shear force on the connection and $M_{\mathrm{c}}$ is the restraining moment.

Table 2 contains a summary of the results for the 15 experiments. The last column shows the total vectorial bearing forces on each of the two screws. In most of the tests, these values were lower than the shear capacity of G14-20TPI screws (12.2 kN (Huynh et al. 2017)). It can be seen that the forces did not transfer equally to the two screws. However, the differences were inconsequential.

Plots of the maximum shear $(F)$ and moment $(M)$ at the connection for the different running ratios are found in Fig. 13. In addition, the shear and moment versus the rotation at screw failure is provided in Fig. 14. Typically, a higher running ratio resulted in a lower shear at failure and a higher restraining moment.

For the case of two actuators moving at the same rate, the experiment may be considered as a pure shear connection test. However, it was found that there was an induced moment as the connection could not act as a simple pin. As can be seen in Fig. 12a, the moment was negative, 
which meant the connection was no longer restraining the beam. This moment with a maximum negative value of $-0.595 \mathrm{kNm}$ was small compared with the beam's bending moment capacity $(21.4 \mathrm{kNm})$.

Fig. 15 shows the vertical, horizontal and vectorial bearing force obtained from the components in Eqs. (3) \& (4) acting on the bottom screw for various running ratios. On the right hand side are photos showing the deformation of the holes. The components of the bearing force on each screw are found later in this paper. From $1.00 \mathrm{x}$ to $3.25 \mathrm{x} R R s$, the force acting on the screws transforms from vertical to an almost horizontal bearing force. With an average rotation at failure of $1.72^{\circ}$ for the $3.25 \mathrm{x}$ case, the experiments show the dramatic effect of the beam's rotation on the behaviour of the screwed connections.

\subsection{Series 2: Bearing and Tilting}

The behaviour of the tests in Series 2 was more complicated compared with Series 1. Initially, the load responses were similar to Series 1: the forces from both actuators increased gradually in the slippage stage, followed by an elastic region and a plastic region. The transition between elastic and plastic zones happened when the load was about 50-60\% of the peak load. For each running ratio, the peak loads in the experiments from Series 2 occurred when the actuators' displacements were about three times larger than the experiments with the same $R R$ from Series 1 . This shows that there were significant amount of bearing deformation at the screws' locations. Because of the small thickness of the channel in Series 2, bearing and tilting could continue after peak loads, leading to a second or third peak (Fig. 16b). In several experiments, one of the two screws failed in shear at the first peak load (Fig. 16a).

The experiments were stopped after failure of the screws or when the deformation of the system reached its limit. For the tests with low $R R$, the limit was when the propagation of the bearing holes reached the longitudinal web stiffeners of the SC20012 channel (Fig. 17b). For tests with high $R R$ (2.50x to $3.25 \mathrm{x}$ ), the limit was when the bottom of the channel was about to contact with the RHS due to large rotation of the connection. The tests with high $R R$ usually gave a ductile behaviour with no clear indication of failure or second peak load (Fig. 16c).

From the loads in the two actuators, shear and moment at the connection can be calculated using Eqs. (1) and (2). Three examples are shown in Fig. 19. Similar to Series 1, when the $R R$ is $1.00 \mathrm{x}$, the restraining moment was negative indicating an applied moment. In the case of (c) with an $R R$ 
of 2.5, the restraining moment was positive as expected. Even though 1.00x_Run2 test had considerably higher actuators' displacements than of 1.00x_Run1 test (Fig. 16a,b), the rotation of the channel at peak load was similar between 2 tests (as can be seen in Fig. 19a,b). The rotation decreased after peak load as only bearing displacement in horizontal direction could translate into rotation of the channel. Therefore, most of the bearing shown in Fig. 17b occurred in the post failure zone in Fig. 19b. The higher the $R R$, less shear force and more restraining moment were applied to the connection, hence the horizontal bearing force became more significant. Fig. 18 shows the horizontal tilting of the screws with the screws pointing in opposite directions. This indicates a couple where the moment was applied.

Table 3 contains a summary of the results from the 15 tests in Series 2. The bearing forces in each screw were calculated from the shear force and moment using Eqs. (3) and (4) and are shown in the last column. It can be seen that the forces were higher than the shear capacity of G14-20TPI screws (12.2 kN (Huynh et al. 2017)) in several tests. The possible explanation is when the screws tilted, the shear surface became an ellipse shape and had larger area than the normal cross-sectional area as similar phenomenon was observed in the simple screw shear experiments (Huynh et al. 2018a).

The shear force and moment at failure for each test were determined using the method shown in Fig. 10. All of the experimental results are plotted in Figs. 20 and 21. A similar pattern with the results of Series 1 was observed to that for Series 2: the shear capacity of the connection decreased with the increase in rotation. However, the connection still had substantial capacity until the rotation reached about $2.5^{\circ}$. Compared with Series 1 , where the shear dropped significantly at $1.0^{\circ}$, the connection with bearing and tilting behaviour shows more resilience when dealing with rotation. In term of restraining moment, as similar to Series 1, there was a negative moment with low $R R$. This moment with a maximum negative value of $-0.887 \mathrm{kNm}$ was small compared with the bending moment capacity of SC20012 section (10.5 kNm).

Fig. 22 shows the averaged vertical, horizontal and vectorial bearing force acting on the bottom screw for different $R R s$ with the corresponding deformation of the holes. It can be seen that the force acting on the screws transforms from vertical to horizontal with the increasing of $R R s$. There was a horizontal force on the screws in the case of $1.00 \mathrm{x}$ and $1.75 \mathrm{x} R R$, which might be due to slippage in the bolts connecting the channel and the loading system. 
Testing on connections in hot-rolled steels by Astaneh-Asl et al. (2002) and Motallebi et al. (2019) used $0.02\left(1.15^{\circ}\right)$ rad as a predetermined rotation where a beam yielded and a large amount of rotation was to be anticipated. This target rotation was achieved from a non-linear analysis of previous tests (Astaneh-Asl 1989). For cold-formed steel beams, buckling may occur before yielding. Nevertheless, extensive rotation is to be expected when the beam undergoes a plastic hinge; as such, $0.02 \mathrm{rad}\left(1.15^{\circ}\right)$ is also a reasonable target to achieve in cold-formed steel connections. The test results showed that at $1.15^{\circ}$, the connection from Series 1 started to lose a portion (about 15\%) of its shear capacity, while Series 2 maintained its strength.

\section{Development of an Analytical Model}

\subsection{A list of assumptions in the development of the model}

This section describes the process of building a theoretical model for the above experimental results. The model uses a constitutive relationship between bearing force and bearing deformation in a single sheared screw (Section 4.2), together with kinematics and statics of the connection (Section 4.3), to establish a relation between shear and rotation of simple connections at failure. In order to build an analytical model for the experimental results, the following assumptions need to be taken into consideration:

- The behaviour of the screws in the connections was assumed to be the same as the simple experiments for the screws in shear described by Huynh et al. (2018a). These simple shear tests used two screws connecting two sheet steels with thicknesses identical to the channel and the angle cleat in the full connection tests.

- Finite Element modelling using Abaqus models calibrated against the simple shear experiments (by Huynh et al. $(2017,2019)$ ) is used to determine the displacement at the bearing holes. The FE model is required because the measurements using LVDTs in the experiments included the elastic deformation of the sheet steels in the bearing deformation. It is necessary to eliminate the elastic component in the model. The shear force and displacement at failure derived from the FE model are used in the theoretical model.

- The direction of the bearing force always follows the travel path of the bearing hole. This assumption is based on the observed behaviour that the direction of the applied loads on the Actuators A and B were unchanged throughout the experiments. Furthermore, the total rotation of 
the channel was less than 6 degrees in all of the tests, hence the travel path of each screw can be considered as a straight line.

- The bearing force can be broken down into vertical and horizontal components, which induced the shear force and bending moment in the connection.

- The moment acting on the angle cleat produced an amount of rotation which can be calculated using elastic twisting theory or strip theory applied to the angle cleat.

\subsection{Bearing displacement at a connector}

Because the experiments ended with the screws failing in shear or tilting and bearing, the failure behaviour of the screws governs the failure mechanism of the connections. This behaviour was investigated previously using simple screwed connection tests performed at the University of Sydney (Huynh et al. 2018a). Finite Element models were also developed and validated with the experimental results (Huynh et al. 2019). The FE models were required as it was difficult to measure directly the displacements at the screw's location without including the elastic deformation of the sheet steels during the actual experiments. The relation between bearing force and bearing displacement of the screws is essential to investigate the behaviour of the connections.

In the simple screwed connection tests (Huynh et al. 2018a), displacements were measured by transducers (LVDTs) at two ends of the connection so this displacement is the sum of the displacement at the connector and the elastic elongation of the sheet steels between the LVDTs. The displacement of a connector can be defined as the total displacement of the steel sheets on two sides of the screw as can be seen in Fig. 23. The simulation was used to generate the loaddisplacement curve for an individual screw in bearing to eliminate the effect of elongation in the sheets.

The FE model simulated exactly the dimensions of the G14-10TPI screws and the sheet steels and was calibrated against the simple connection experiments. The model was built and implemented using the Abaqus/CAE 6.14-1 enviroment (Dassault Systèmes 2014). The screws and steel sheets were modelled as 3D solid deformable elements. The screw model contained the screw head and simplified screw threads. Elastic, plastic and fracture behaviour were included in both screws and steel sheets. The explicit solver from Abaqus was used because this model included complicated interactions between the screws and the steel sheets. Furthermore, the explicit solver was suitable for converging a solution when the model became highly 
discontinuous, which happened when fractures started to occur. More details about the FE model can be found in previous papers on screwed connection modelling (Huynh et al. 2017, 2018b, 2019), where calibration was carried out based on the load - displacement curve from the experiments.

Two FE models using the G14-10TPI screws and different sheet steels matching with the channel and the angle cleat from the two test series were developed. In the first model, the sheet in contact with the screw heads is changed to match the thickness of the angle cleat $(4.0 \mathrm{~mm})$, and the other sheet using the thicknesses of the C20024 section $(2.4 \mathrm{~mm})$ from Series 1 . The second model has the screws connecting the thin sheet $(1.2 \mathrm{~mm}$ - thickness of the SC20012 section from Series 2) with the thick sheet $(4.0 \mathrm{~mm})$ acting as a base. Material properties were taken from coupon tests and input into ABAQUS as true stress-strain curves.

Fig. 24 shows the bearing displacements from the FE models just before fracture of the screws. Even though both models end up with the screws failing in shear, the amount of bearing in the second model (Fig. 24b) is much larger than the first model (Fig. 24a). There is very little deformation of the steel sheets in the first model, where the hole still has a round circle shape after failure. On the other hand, the second model shows materials piling up in front of the screws and a considerable amount of tilting.

Fig. 25(a) gives the load-displacement response from the first FE model with the total displacement at the two ends of the connection and Fig. 25b gives the bearing displacement of the screw alone $\left(d_{\mathrm{b}}\right)$. The load response in Fig. 25a is apparently more ductile as it includes the effect of elastic elongation in the sheets. After failure and the load returns to zero, the two graphs end at the same displacement of about $2.5 \mathrm{~mm}$ because the steel sheets - carrying no load - have recovered to their original shape. It can be seen that the screw failed at a net bearing displacement $d_{\mathrm{b}}$ of about $1.7 \mathrm{~mm}$ and a bearing load of $V_{\mathrm{b}}=12.2 \mathrm{kN}$.

Fig. 26 shows the load-displacement curves from the second FE model. The ultimate load is higher than the shear capacity of G14-10TPI screw (12.2 kN (Huynh et al. 2017)) because when tilting occurs before failure, the load in the screw includes both shear and an amount of tension. Fracture occurs in one screw and another right after that, hence there is the disruption with the 
drop down region of the load. The screw failed at a net bearing displacement of $d_{\mathrm{b}}=4.5 \mathrm{~mm}$ and a bearing load of $V_{\mathrm{b}}=14.0 \mathrm{kN}$.

\subsection{Rotation of the channel based on bearing displacement at the connectors}

The next step in developing the model is finding the rotation of the channel. Initially, the angle cleat (AC) is assumed to be rigid, hence the movement of the C-channel is purely due to bearing displacement of the screws. Fig. 27a shows the assumed vertical movement and rotation of the Cchannel. Fig. 27b shows the displacement of the top and bottom screws.

Defining these variables:

- D : distance between two screws (160 mm for Series 1, $115 \mathrm{~mm}$ for Series 2),

- $S S_{1} \quad$ : horizontal displacement of the top screw due to rotation of the channel,

- $S_{1} S_{2} \quad$ : vertical displacement of the top screw due to rotation of the channel,

- $S_{2} S_{3} \quad$ : vertical displacement of the top screw due to vertical motion of the channel,

- $S R_{1} \quad$ : horizontal displacement of the top screw due to rotation of the cleat angle,

- $R_{1} R_{2}$ : vertical displacement of the top screw due to rotation of the cleat angle,

- $R_{2} S_{3}$ : total bearing displacement at the top screw at failure,

- $U U_{1}$ : horizontal displacement of the bottom screw due to rotation of the channel,

- $U_{1} U_{2}$ : vertical displacement of the bottom screw due to rotation of the channel,

- $U_{2} U_{3}$ : vertical displacement of the bottom screw due to vertical motion of the channel,

- $U T_{1}$ : horizontal displacement of the bottom screw due to rotation of the cleat angle,

- $T_{1} T_{2}$ : vertical displacement of the bottom screw due to rotation of the cleat angle,

- $T_{2} U_{3}$ : total bearing displacement at the bottom screw at failure,

- $\theta \quad$ : angle of rotation of the channel,

- $\varepsilon \quad$ : angle of rotation of the angle cleat,

- $\alpha \quad$ : angle made up of the bearing displacement path $\left(R_{2} S_{2}\right)$ and the horizontal axis,

- $\beta \quad$ : angle made up of the screw bearing force and the horizontal axis,

- $d_{\mathrm{b}} \quad$ : total bearing displacement on the screw at failure,

- $V_{\mathrm{b}} \quad$ : total bearing force on the screw at failure,

- $V_{\mathrm{v}}, V_{\mathrm{h}}$ : vertical and horizontal components of the bearing force of the screw,

- F, $M$ : total shear force and moment acting on the connection. 
By kinematics, the bearing displacement of the top screw $\left(R_{2} S_{3}\right)$ can be broken down into vertical and horizontal displacements as shown in Fig. 28. These components, representing in terms of displacement of the cleat angle and the channel, are shown in the following equations:

$$
\begin{gathered}
\left(R_{2} S_{3}\right)_{h}=S S_{1}-S R_{1} \\
\left(R_{2} S_{3}\right)_{v}=S_{1} S_{3}-R_{1} R_{2}
\end{gathered}
$$

In order to derive the relation between force, moment and rotation, an assumption was made: bearing force always points in the $\mathrm{R}_{2} \mathrm{~S}_{3}$ direction, which brings about $\alpha=\beta$ (Fig. 28). This assumption is very likely to be true as the direction of the apply loads on Actuators A and B were unchanged through the experiments. Furthermore, total rotation of the C-channel is less than 2 degrees in all of the tests, hence the travel path of the screw can be considered as a straight line. Similar interpretation can be applied for the bottom screws, which gives bearing force on the bottom screw always points in the $T_{2} U_{3}$ direction.

As the forces from the actuators in experiments were acting vertically, the sum of horizontal forces was neutral. Therefore, $R_{1} S_{1}$ (or $\left.\left(R_{2} S_{3}\right)_{\mathrm{h}}\right)$ and $T_{1} U_{1}$ (or $\left.\left(T_{2} U_{3}\right)_{\mathrm{h}}\right)$ must be equal because the horizontal component of bearing forces is proportional to horizontal displacement. Hence the channel had to move a distance of $(H / 2) \sin (\varepsilon)$ to the right as shown in Fig. 27b. This movement was permitted in the experiments because of the flexible restraining system.

With the small angles of rotation, the curves $S S_{2}$ and $U U_{2}$ can be considered as straight horizontal lines $\left(S_{1} \equiv S_{2}\right.$ and $\left.U_{1} \equiv U_{2}\right)$. Hence the bearing displacements of the top screw $\left(R_{2} S_{3}\right)$ and bottom screw $\left(T_{2} U_{3}\right)$ are equal (and equal $d_{\mathrm{b}}=1.70 \mathrm{~mm}$ for Series 1 and $4.5 \mathrm{~mm}$ for Series 2). The kinematic relationship between the horizontal component of bearing displacement $\left(R_{2} S_{3}\right)_{\mathrm{h}}$ and the vertical component of bearing displacement $\left(R_{2} S_{3}\right)_{\mathrm{v}}$ can be written as:

$$
\begin{gathered}
\left(R_{2} S_{3}\right)_{h}=S S_{1}-S R_{1}=\frac{D}{2}(\theta-\varepsilon) \\
\left(R_{2} S_{3}\right)_{v}=\sqrt{\left(R_{2} S_{3}\right)^{2}-\left(R_{2} S_{3}\right)_{h}^{2}}=d_{b} \sqrt{1-\left(\frac{D(\theta-\varepsilon)}{2 d_{b}}\right)^{2}}
\end{gathered}
$$

Then vertical and horizontal bearing forces can be calculated from statics: 


$$
\begin{gathered}
V_{v}=V_{b} \sin (\alpha)=V_{b} \sqrt{1-\left(\frac{D(\theta-\varepsilon)}{2 d_{b}}\right)^{2}} \\
V_{h}=V_{b} \cos (\alpha)=V_{b}\left(\frac{D(\theta-\varepsilon)}{2 d_{b}}\right)
\end{gathered}
$$

With:

$$
V_{h}^{2}+V_{v}^{2}=V_{b}^{2}
$$

\subsection{Rotation of the angle cleat $(\theta)$}

Finally, the rotation of the angle cleat $(\varepsilon)$ is incorporated into the equation. The rotation of the AC can be calculated using the twisting of the free part shown in Red in Fig. 29 that is not restrained by the bolts’ washers. The moment caused by the bearing forces at the corner is:

$$
M_{1}=D \times V_{h}+\left(D_{1} / 2\right) \times 2 V_{v}=D V_{h}+D_{1} V_{v}
$$

Considering a rectangular section between the washers and the corner (the red lines in Fig. 29): the bending moment $M_{1}$ twists that plate and induces a rotation of the outer side of the bracket. The plate can be considered as a beam with a cross-section of $H \times t$ and a length of $L$ undergoing twisting by the effect of the torque $M_{1}$.

Its rotation - also the rotation of the AC, can be represented as:

$$
\varepsilon=\frac{k M_{1} L}{G J}=\frac{6 k(1+v)}{E_{t}^{3}}\left(\frac{L}{H}\right) M_{1}=\frac{6 k(1+v)\left(\frac{L}{t}\right)^{3}}{E H L^{2}} M_{1}
$$

in which $k$ is a ratio between the amount of rotation with the bottom end restrained and the rotation when there is no restraint. Using FE modelling in Abaqus, it is estimated that $k=0.695$. $J$ $=H t^{3} / 3$ is the torsional constant of the rectangular plate, and $\mathrm{G}=\mathrm{E} / 2(1+v)$ where $v$ is the Poisson's ratio.

The relationship between $V_{\mathrm{h}}$ and $\theta$ can be found by substituting Eqs. (11), (12) and (13) into Eq. (10): 


$$
V_{h}=V_{b} \frac{D}{2 d_{b}}\left[\theta-\frac{k L}{G J}\left(D V_{h}+D_{1} \sqrt{V_{b}^{2}-V_{h}^{2}}\right)\right]
$$

Expanding and solving Eq. (14) gives:

$$
V_{h}=\frac{\frac{D \theta}{2 d_{b}}\left(1+\frac{D}{A}\right) \pm \frac{D_{1}}{A} \sqrt{\left(1+\frac{D}{A}\right)^{2}-\left(\frac{D \theta}{2 d_{b}}\right)^{2}+\left(\frac{D_{1}}{A}\right)^{2}}}{\left(1+\frac{D}{A}\right)^{2}+\left(\frac{D_{1}}{A}\right)^{2}}
$$

where $A$ is a parameter with the unit of length $(\mathrm{mm})$ :

$$
A=\frac{2 d_{b} G J}{k D L V_{b}}=\frac{E d_{b} H L^{2}}{2 k(1+v) D V_{b}\left(\frac{L}{t}\right)^{3}}=\frac{E d_{b} t^{3}}{3 k(1+v) D V_{b}}\left(\frac{H}{L}\right)
$$

The vertical bearing force can be calculated from Eq. (11):

$$
V_{v}=\sqrt{V_{b}^{2}-V_{h}^{2}}
$$

Hence the shear force and moment at the connection are:

$$
\begin{gathered}
F=2 \times V_{v} \\
M=D \times V_{h}
\end{gathered}
$$

In order to calculate the rotation at the connectors when the screws fail, another assumption about the constitutive relationship between bearing force and displacement is used: the screw in the experiments reached maximum load of $12.2 \mathrm{kN}$ at $1.70 \mathrm{~mm}$ displacement for Series 1 (Fig. 25). These numbers will be used for all the calculations in this theoretical model. From Eqs. (18) and (19), the relationship between shear force, moment and rotation of the C-channel is graphed in Fig. 30.

The distance from the edge of the washers to the corner of the AC is $L=3 \mathrm{~mm}$ as shown in Fig. 29. However, the washers can only restrain a portion of the rectangle. Therefore, it may be 
reasonable to assume that a higher value of $L$ may be able to be used so that Fig. 30 also includes $L=5 \mathrm{~mm}$ and $L=10 \mathrm{~mm}$ for comparison. Also the experimental results from Series 1 are included for comparison. It is visible from Fig. 30(I) that all data points from the tests are located around the curve of $L=3 \mathrm{~mm}$. Therefore $L=3 \mathrm{~mm}$ is a reasonable parameter in the twisting theory and will be chosen for later comparison with the results from Series 2 .

Considering the shear-rotation curve for $L=10 \mathrm{~mm}$ as shown in Fig. 30.0, there are four critical points on the graph. $L=10 \mathrm{~mm}$ was chosen for demonstration as the critical points can be shown more clearly. They can be calculated as followed:

- Point (a): when $\theta$ is zero, $V_{\mathrm{h}}$ is negative:

$$
\begin{aligned}
& V_{h}=\frac{-\frac{D_{1}}{A}}{\sqrt{\left(1+\frac{D}{A}\right)^{2}+\left(\frac{D_{1}}{A}\right)^{2}}} V_{b} \\
& V_{v}=\frac{1+\frac{D}{A}}{\sqrt{\left(1+\frac{D}{A}\right)^{2}+\left(\frac{D_{1}}{A}\right)^{2}}} V_{b}
\end{aligned}
$$

- Point (b): maximum vertical force $\left(V_{\mathrm{v}}=V_{\mathrm{b}}\right)$ and zero horizontal force $V_{\mathrm{h}}$, hence the point of maximum shear force and zero bending moment. The corresponding rotation is:

$$
\theta=\frac{6 k(1+v)}{E t^{3}}\left(\frac{L}{H}\right) D_{1} V_{b}
$$

- Point (c): maximum rotation of the channel $\theta$, with $\theta_{\max }$ and $V_{\mathrm{v}}$ as:

$$
\theta_{\max }=\frac{2 d_{b}}{D} \sqrt{\left(1+\frac{D}{A}\right)^{2}+\left(\frac{D_{1}}{A}\right)^{2}}
$$




$$
V_{v}=\frac{\frac{D_{1}}{A}}{\sqrt{\left(1+\frac{D}{A}\right)^{2}+\left(\frac{D_{1}}{A}\right)^{2}}} V_{b}
$$

- Point $(d)$ : zero shear force and maximum bending moment, the corresponding rotation is:

$$
\theta=\frac{2 d_{b}}{D}\left(1+\frac{D}{A}\right)
$$

From point (a) to point (c), Eq. (15) has a negative sign before the square root term. The square root term becomes zero at point (c) and the sign switches to positive from (c) to $(d)$. Beyond this angle, the connection will fail without carrying any shear force. The bearing force has only a horizontal component.

Fig. 31a shows a comparison of the actual rotations of the AC $(\varepsilon)$ and the C-channel $(\theta)$ on the horizontal axis. Fig. 31b shows the relative rotation $(\theta-\varepsilon)$ of the C-channel compared with the angle cleat. The relationship in Fig. 31b is the same for every value of $L$. The negative zone occurs when the angle cleat has larger absolute rotation than the channel.

\subsection{Comparison with Experimental Results}

From the established equations (Eqs. (15)-(19)), comparisons between experimental results and the analytical model can be carried out. The controlling parameters in the model are $V_{\mathrm{b}}, d_{\mathrm{b}}$ and $D$, which were different between the two test series and are shown in Table 4. The theoretical curves for each series can be constructed by substituting the numbers into Eqs. (15) and (16).

Fig. 32 shows the relation between shear force and rotation at failure for both test series. In Series 1 , the shear capacity of the connection decreases quickly when the rotation reaches $1.5^{\circ}$. In Series 2, the drop occurs at about $3.0^{\circ}$. At $3.0^{\circ}$, a typical purlin may already form a plastic hinge at the mid-span. Therefore, the connection in Series 2 can maintain its strength in circumstances with demanding rotations.

The results from the analytical model are also shown in Fig. 32, which have good agreement with the experimental results. From the model, it can be seen that the bearing displacement $d_{\mathrm{b}}$ is the main criterion that affects the shear - rotation relation: it controls how much rotation a connection can experience before losing its shear capacity. In Series 2, the model shows more 
flexibility compared with the test results. The possible explanation is the value of $d_{\mathrm{b}}$ used in the model is higher than the actual bearing deformation in the experiments. The bearing displacement in Series 2 tests can be seen in Fig. 22, which had a high amount of variation compared with Series 1 (Fig. 15). A more carefully calibrated FE model may be able to yield a better result for $d_{\mathrm{b}}$, hence an improved model results for Series 2.

Fig. 33 shows the moment versus rotation comparison between the experimental results and the analytical model for both test series. The model can match the test results at higher rotations. For the tests with low running ratios ( $R R s)$, there is a negative moment which cannot be replicated using the model. However, this moment is very small compared with the bending moment capacity of the channels. Furthermore, the connections with two screws used in the experiments was designed to transfer shear force only, hence an investigation of bending moment is not an essential assignment of these test series.

Fig. 34 shows the results when applying the distances between the two screws from Series 1 into the model for Series 2 and vice versa. The results show that the screw spacing does affect the connection rotation ductility by $15 \%$ for Series 1 and $20 \%$ for Series 2 . However, the effect of the screw failure mode can still be seen in Fig. 34 to play the most significant role where the reduction in ductility for Series 2 to Series 1 is $62 \%$.

The developed model shows that when the rotation reaches $1.0^{\circ}$, the connection in Series 1 loses $10 \%$ of its shear capacity while the connection in Series 2 still has $99 \%$ of its capacity. The connection from Series 1 loses all of its strength when the rotation is $1.9^{\circ}$. On the other hand, the connection from Series 2 loses $10 \%$ of its strength when the rotation reaches $2.4^{\circ}$ and only gives up carrying shear when the rotation is $5.1^{\circ}$. The resilience of the specimens in Series 2 is noticeably higher than Series 1 when dealing with high rotation. Furthermore, the model shows that the connection achieves maximum shear capacity at a rotation slightly above zero $\left(0.19^{\circ}\right.$ for Series 1 and $0.22^{\circ}$ for Series 2 ).

\section{Design Recommendations}

In the analytical model, the ductility comes from the bearing behaviour of the connectors, the flexibility of the angle cleat and the distance between the connectors. Usually a connection designer may want to increase the distances between connectors for a possible higher moment 
capacity. However, for a simple connection that is designed for shear only, a lower spacing between the connectors helps conserve its shear capacity when dealing with rotation, provided that the distances between the connectors are not too close for the "group effect" to impact their combined strength (Li et al. 2010) and the connection to become laterally unstable.

Astaneh-Asl et al. (1993) proposed a design guideline for single plate shear connections that checked for failure of bolt holes, bolt and weld fracture, plate yielding, fracture of net section of plate and fracture of edge distance of plate. A requirement in this method is that the connection has to be able to provide a sustainable rotational ductility. The authors stated that the design procedure should induce more ductile failure modes occurring before brittle failure mode or failure involved fracture of the material. The model in this paper suggests another design check for connection design in cold-formed steels: shear capacity versus rotation of the connection. The rotation target can be the serviceability rotation, the elastic rotation at two ends of a simply supported beam or the rotation when there is a plastic hinge. The designer should check that the connection provides adequate strength at these rotations, especially in the case of possible brittle failure as in Series 1. Besides designing connectors that fail in bearing and tilting, rotational ductility can be improved by using a slender angle cleat, reducing spacing between the connectors or reducing the number of connectors (Experimental results by Astaneh-Asl et al. (1993) showed that rotational ductility decreased with the increase in the number of connectors).

In the experiments in this paper, the connection should be considered as a simple connection as the restraining moment was less than $20 \%$ of the section capacity of the respective beam: $1.8 \mathrm{kNm}$ and $21.4 \mathrm{kNm}$ respectively in Series 1; $1.5 \mathrm{kNm}$ and $10.5 \mathrm{kNm}$ respectively in Series 2. Therefore, a shear versus rotation design check is recommended in shear connection design in cold-formed steels. The analytical model in this paper requires equation solution solving (Eq. (14)). However, the design process can be simplified by substituting the required shear strength into Eq. (12) and working out the corresponding rotation from Eq. (13) and check if the rotation reaches its limit. The bearing displacement of the screws can be determined from simple screwed connection tests provided that transducers are placed close enough to the connectors to avoid additional deformation from the sheet steels. These processes may simplify the shear-rotation check step. Furthermore, this step can be excluded entirely if the connection shows adequate rotational ductility or plastic hinge in the beam is shown to be preventable. 
According to AS/NZS 4600-2018 (Australian/New Zealand Standard 2018), where the composition or configuration of a connection cannot be made in accordance with the table for capacity reduction factor, or there is insufficient testing data, the design capacity shall be determined using the factor of $\phi=0.65$. For the connections used in this paper, the governed mode of failure was failure of the connectors, hence the capacity reduction factor for screwed connections fail in tilting and hole bearing may be used: $\phi=0.50$.

In the design of cold-formed steel floor joists, both the strength and deflections limits need to be checked. In the case of the C20024 and SC20012 beams used in this study, the deflections will depend upon the floor loading and beam spacing in addition to the second moments of area of the beams studied. If a conventional design deflection limit of 1/8 inch (3.175mm) is assumed, then the length of span to satisfy the serviceability limit of L/500 is $1.588 \mathrm{~m}$. To estimate possible deflections at different spans, a floor live load of $3.0 \mathrm{kPa}$ and a floor dead load of $2.0 \mathrm{kPa}$ as specified in AS/NZS 1170.1:2002 (Standards Australia 2002) have been assumed. For the C20024 beam tested in this study, the lengths of beam to satisfy the deflection limit above are $2.73 \mathrm{~m}, 3.25 \mathrm{~m}$ and $4.08 \mathrm{~m}$ for beam spacings of $1.0 \mathrm{~m}, 0.5 \mathrm{~m}$ and $0.2 \mathrm{~m}$ respectively. Consequently this beam size meets the serviceability requirement of L/500 for all spans. For the SC20012 beam tested in this study, the lengths of beam to satisfy the deflection limit above are $2.30 \mathrm{~m}, 2.73 \mathrm{~m}$ and $3.43 \mathrm{~m}$ for beam spacings of $1.0 \mathrm{~m}, 0.5 \mathrm{~m}$ and $0.2 \mathrm{~m}$ respectively. Consequently, this beam also satisfies the serviceability requirement of L/500 for all spans. It is also assumed that the restraint from the screwed end connections studied in this paper do not provide significant additional rotational restraint to limit these deflections.

\section{Conclusion}

This paper presents two test series for shear connections using angle cleats. There were 15 experiments in each series in order to establish the relation between the connection's rotation and shear capacity. The components of the connection were unchanged through the two series, only the thickness of the connected beam and the distance between the two screws were adjusted. Experimental results from both series showed that there was a reduction in shear capacity of the connection when its rotation increased. The connection almost lost its shear capacity entirely when the rotation reached $1.7^{\circ}$ for Series 1 and $4.5^{\circ}$ for Series 2 . 
Test results from the two series showed that changing one component of a connection system will dramatically alter its behaviour. The behaviour of individual components, especially the connectors in this test series, has a remarkable effect on the structural behaviour of the whole system. In structural design, bearing and tilting behaviour is preferable than fracture of the screws as the former is involved with ductile failure whilst the latter is brittle failure. Even though there were several tests in Series 2 that ended up with screw failure in shear, the deformations before failure in these tests were still significantly higher than in the Series 1 tests. Ductile behaviour is preferable as it gives warning before complete failure of the structure, especially for the case where there is a plastic hinge in the beam. In this case, even though the load does not increase, the beam rotation keeps advancing. The flexible components in the Series 2 connections allow them to preserve their shear strength and prevent the structure from total collapsing. Furthermore, it can be seen that failure of the sheet steels (in the channel or angle cleat) is preferable to brittle failure of the connectors.

This paper also presents an analytical model including the combined effect of rotation of the channel and twisting of the angle cleat. The difference in behaviour between the two series came from the bearing force of the screws, the bearing displacement and the distance between the screws. The model provided an additional criterion in designing shear connections in addition to the established design checks in current design guides. There was only one type of angle cleat used in this study. The authors suggest further studies into angle cleats with different thicknesses and dimensions be carried out which will enhance the knowledge on shear connections and can be combined into a design guideline for designing hybrid connections in cold-formed steel.

\section{Data Availability Statement}

No data, models, or code were generated or used during the study.

\section{Acknowledgements}

This research was carried out under the research grants "Hybrid steel-framed structural systems for mid-rise buildings” from Australian Research Council /Discovery Projects - (DP 160104640), with the support of the University of Sydney. The first author's research degree was supported by 
the Research Training Program (RTP) Fee Scholarship by the Australian Government. The authors gratefully acknowledge the support.

\section{References}

Astaneh-Asl, A. (1989). "Demand and Supply of Ductility in Steel Shear Connections.” Journal of Constructional Steel Research, 14(1), 1-19.

Astaneh-Asl, A., Liu, J. and McMullin, K.M. (2002). "Behavior and design of single plate shear connections.” Journal of Constructional Steel Research, 58(5-8), 1121-1141.

Astaneh-Asl, A., McMuUin, K.M. and Call, S.M. (1993). "Behaviour and Design of Steel Single Plate Shear Connections.” Journal of Structural Engineering, 119(8).

Australian Standard (1993). "Steel sheet and strip - Hot-dipped zinc-coated or aluminium/zinc coated - AS 1397-1993”. Sydney, Australia, Standards Australia.

Australian/New Zealand Standard (2002). “AS/NZS 1170.1:2002 Structural Design Actions. Part 1: Permanent Imposed And Other Actions." Sydney, Australia, Standards Australia/Standards New Zealand.

Australian/New Zealand Standard (2016). “AS/NZS 1252.1:2016 High-strength steel fastener assemblies for structural engineering-Bolts, nuts and washers. Part 1: Technical requirements.” Sydney, Australia, Standards Australia/Standards New Zealand.

Australian/New Zealand Standard (2018). “Cold-Formed Steel Structures, AS/NZS 4600:2018.” Sydney, Australia, Standards Australia/Standards New Zealand.

BlueScope Steel Limited (2014). “Lysaght Supa Purlins SupaZeds and SupaCees.”

Dassault Systèmes (2014). “Abaqus 6.14 Online Documentation”.

Fox, S.R. (2003). "The Strength of Stiffened CFS Floor Joist Assemblies with Offset Loading Research Report RP03-6”, American Iron and Steel Institute.

Fox, S.R. (2005). "The Strength of CFS Floor Assemblies with Clip Angle Bearing Stiffeners Research Report RP05-6”, American Iron and Steel Institute.

Hogan, T.J. (2007). “Structural Steel Simple Connections - Open Sections Suite.” 1st ed. Australia: Australian Steel Institute.

Huynh, M.T. (2019). "Structural Behaviour of Cold-Formed Steel Screwed Connections." Doctoral thesis, School of Civil Engineering, The University of Sydney, Sydney

Huynh, M.T., Pham, C.H. and Hancock, G.J. (2017). “On the Finite Element Modeling of the Screwed Connections of Cold-Formed Steel.” Proceedings of the 4th Congrès International de Géotechnique - Ouvrages -Structures, Ho Chi Minh City, Vietnam.

Huynh, M.T., Pham, C.H. and Hancock, G.J. (2018a). "Experiments on Screwed Connections in Shear using High Strength Cold-Reduced Sheet Steels.” Eighth International Conference on THIN-WALLED STRUCTURES, Lisbon, Portugal. 
Huynh, M.T., Pham, C.H. and Hancock, G.J. (2018b). "Modelling of Screwed Connections in Shear using High Strength Cold-Reduced Sheet Steels.” Eighth International Conference on THIN-WALLED STRUCTURES, Lisbon, Portugal.

Huynh, M.T., Pham, C.H. and Hancock, G.J. (2019). "Experimental behaviour and modelling of screwed connections of high strength sheet steels in shear." Thin-Walled Structures, 146(106357).

Lawson, R.M. and Ogden, R.G. (2008). "Hybrid light steel panel and modular systems.” ThinWalled Structures, 46(7-9), 720-730.

Li, Y., Ma, R. and Yao, X., (2010). "Shear Behavior of Screw Connections for Cold-formed Thinwalled Steel Structures.” 20th International Specialty Conference on Cold-Formed Steel Structures, St. Louis, Missouri: Missouri University of Science and Technology.

Mirzaei, A. (2014). "Steel shear tab connections subjected to combined shear and axial forces." PhD Thesis, The Department of Civil Engineering and Applied mechanics, Montreal, McGill University.

Motallebi, M., Lignos, D.G. and Rogers, C.A. (2019). "Full-scale testing of stiffened extended shear tab connections under combined axial and shear forces.” Engineering Structures, 185, 90-105.

Rogers, C.A., Marosi, M., Hertz, J., Lignos, D., Tremblay, R. and D’Aronco, M. (2016). "Performance of Weld-retrofit Beam-to-Column Shear Tab Connections." Eighth International Workshop on Connections in Steel Structures, Boston, MA.

Thomas, K., Driver, R.G., Oosterhof, S.A. and Callele, L. (2017). “Full-scale Tests of Stabilized and Unstabilized Extended Single-plate Connections.” Structures, 10, 49-58.

Yarimci, E., Yura, J.A., and Lu, L.W. (1967), “Techniques for Testing Structures Permitted to Sway”, Experimental Mechanics, Volume 7, Number 8, 321-331.

Yu, C., Yousof, M., Mahdavian, M. and Zhang, W. (2016). "Behavior and Design of Thin-Walled Cold-Formed Steel Clip Angles Subjected to Shear Load.” Journal of Structural Engineering, 142(7). 


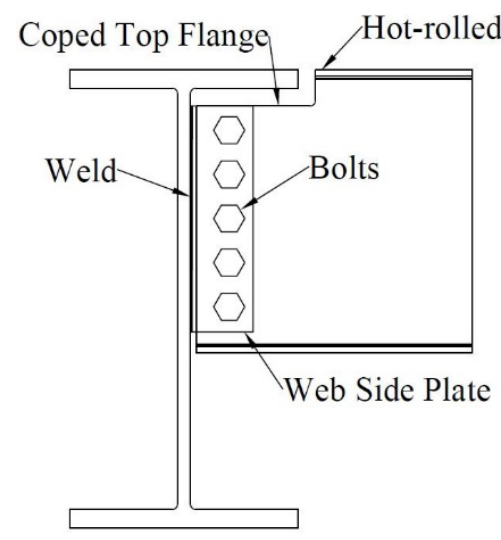

(a)

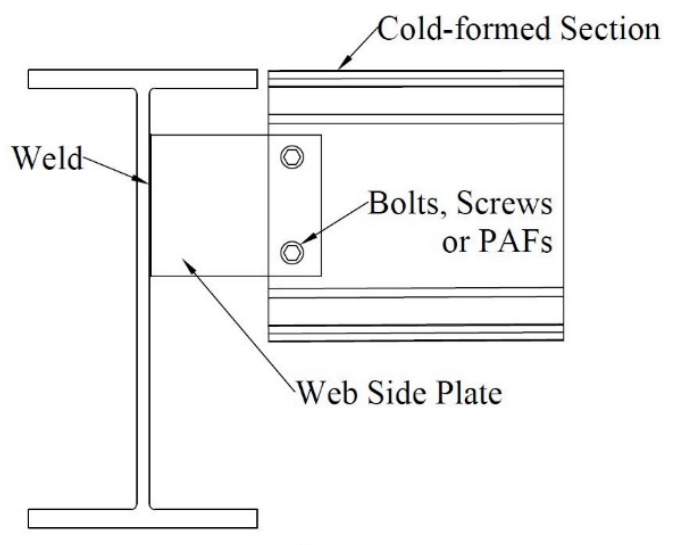

(b)

Figure 1: Typical connections from (a) Hot-rolled steel beams and (b) Cold-formed steel channels to I-beams. 

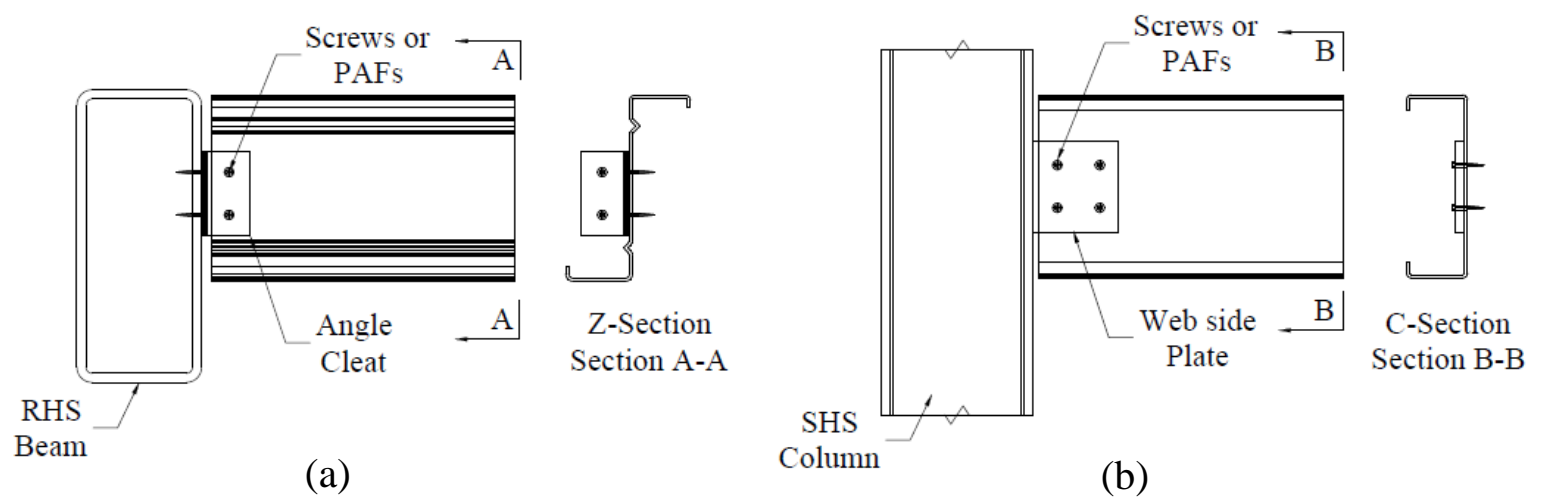

Figure 2: Connections using (a) Angle cleat and (b) Web side plate. 

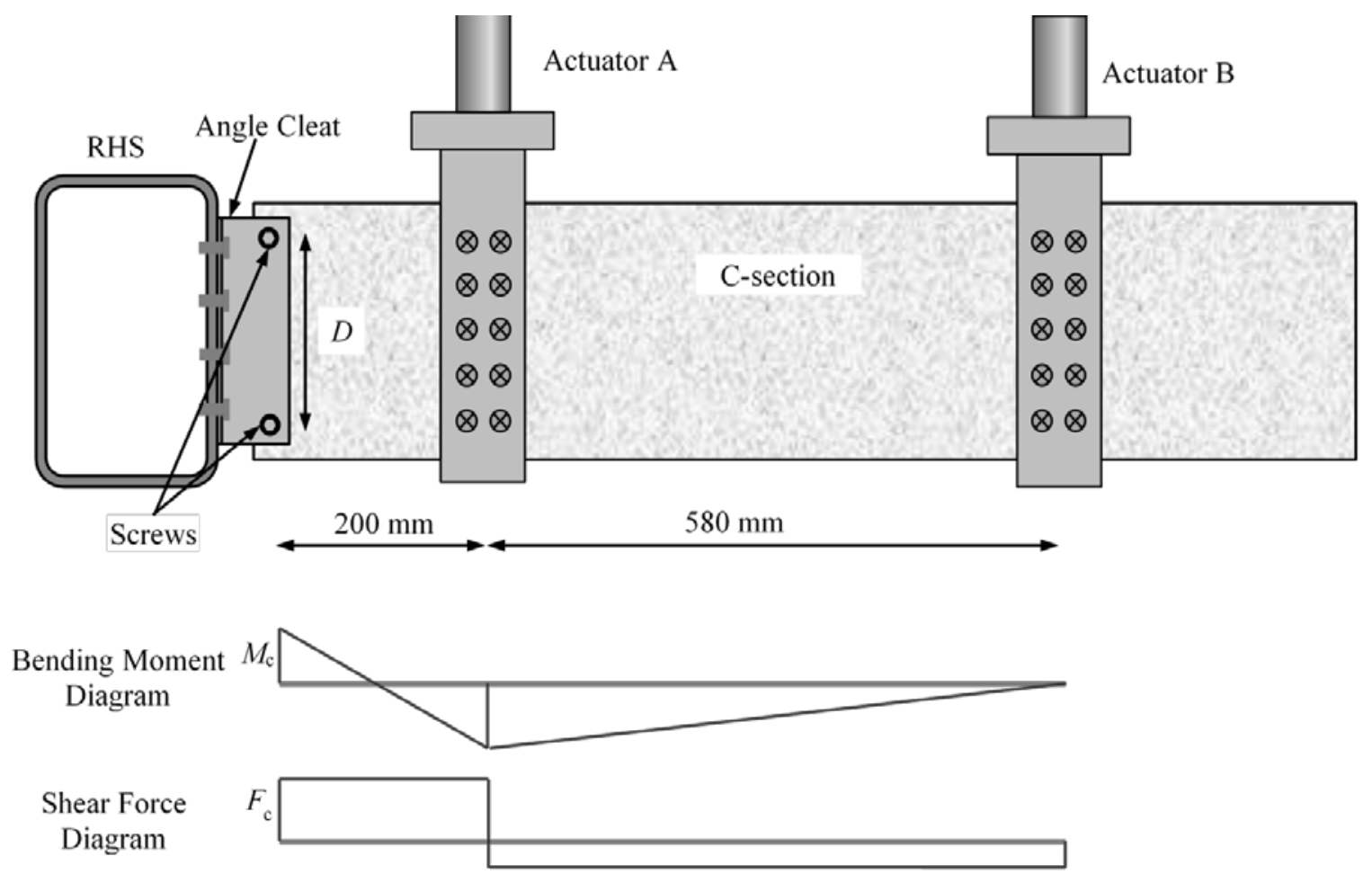

Figure 3: Schematic diagram of the dual actuator test setup. 


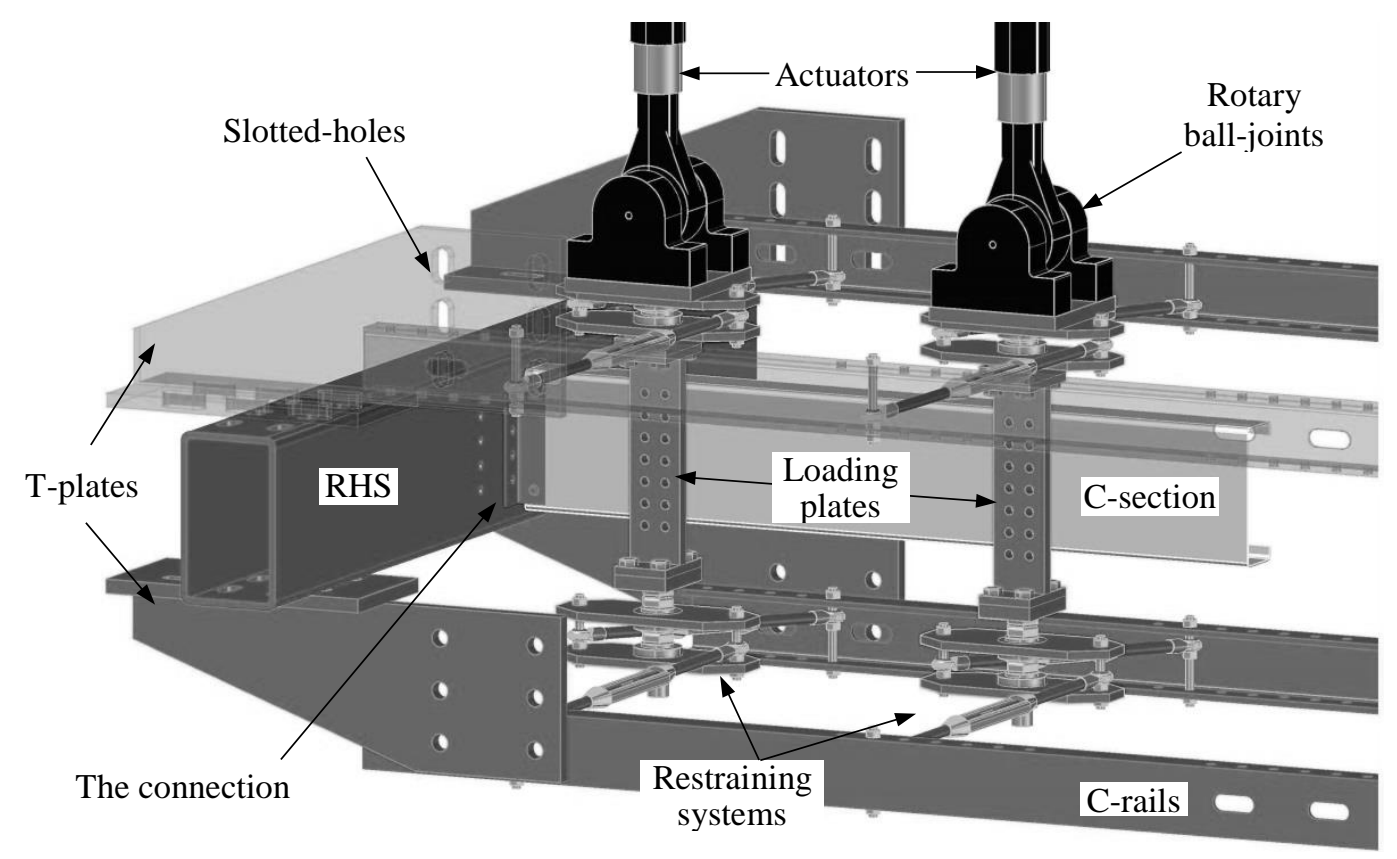

Figure 4: Illustration of the test setup with the support columns removed. 

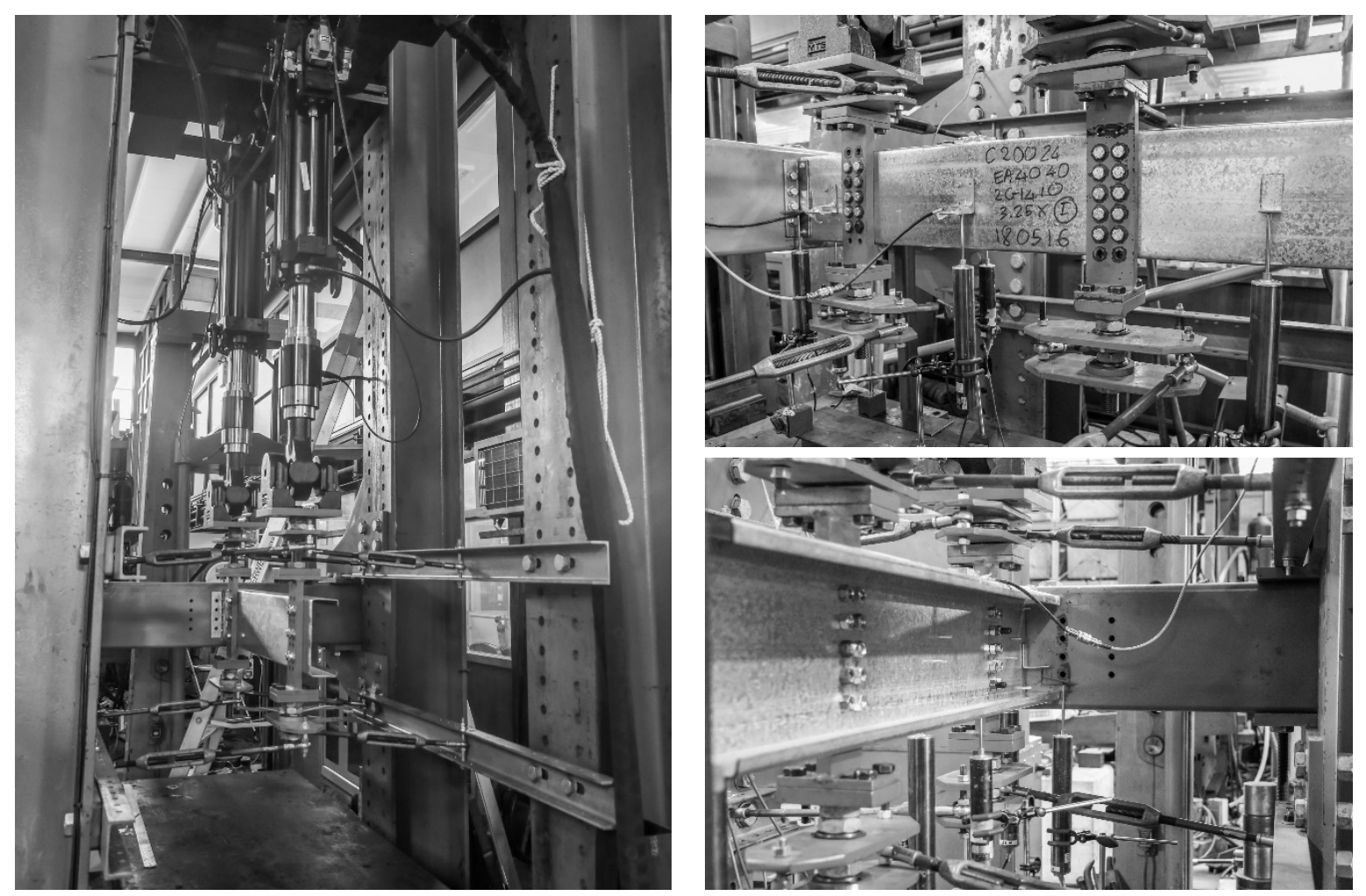

Figure 5: Test setup for connection from cold-formed steel channel to RHS steel beam. 


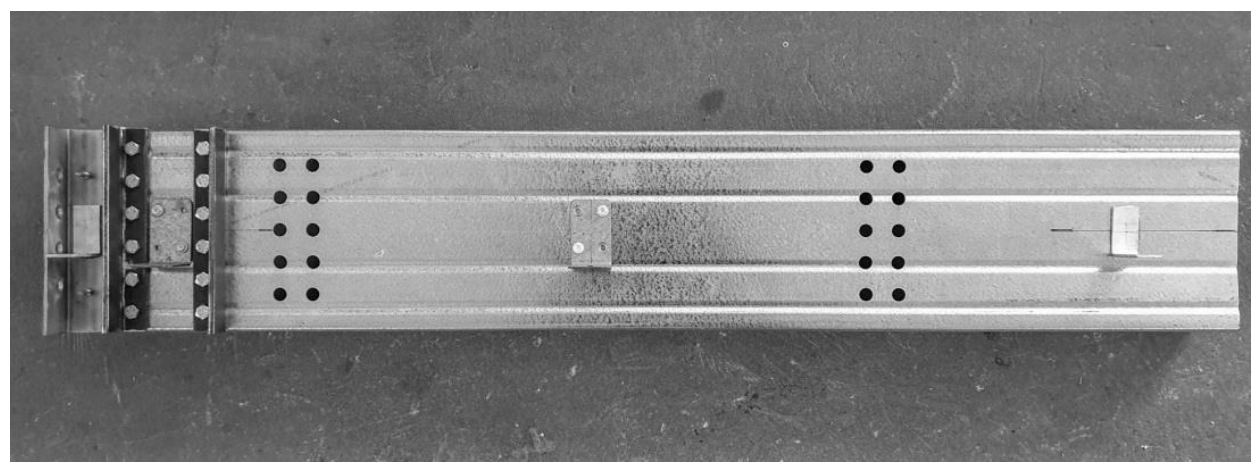

Figure 6: A SC20012 Specimen with the stiffners on the left to prevent local buckling. 


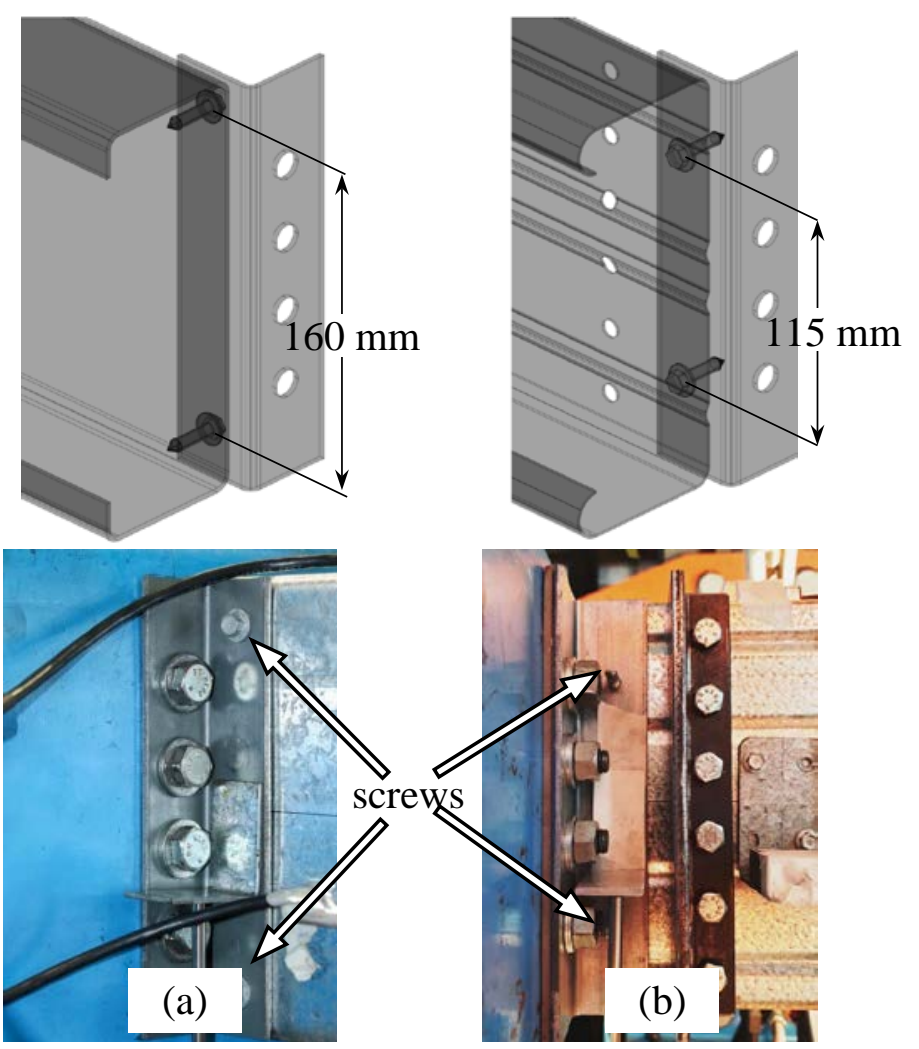

Figure 7: The connection in (a) Series 1 and (b) Series 2. 


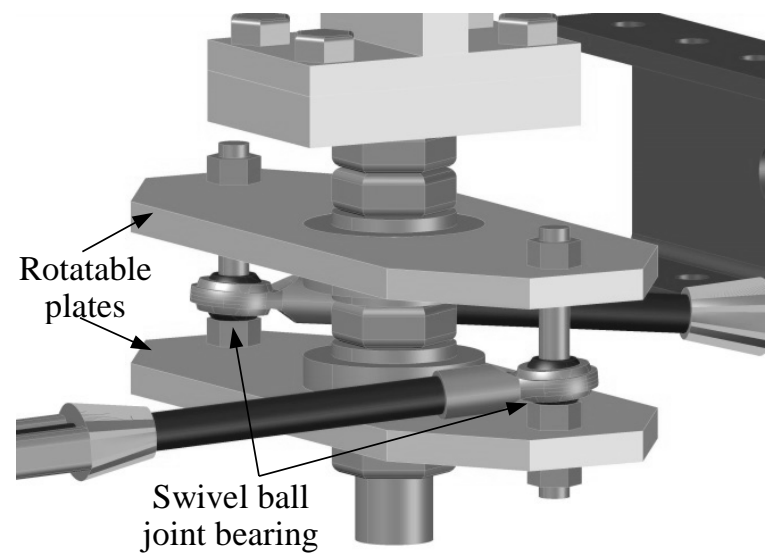

(a) 3D view

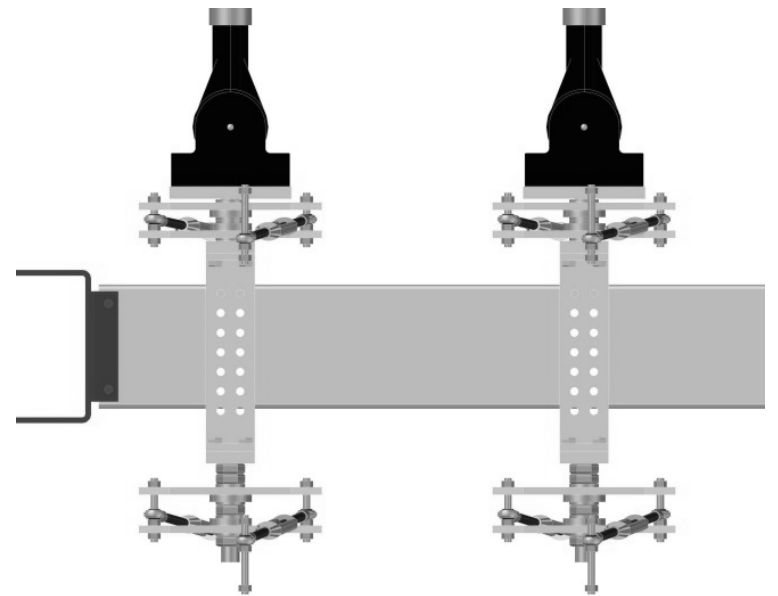

(c) Elevation view - front
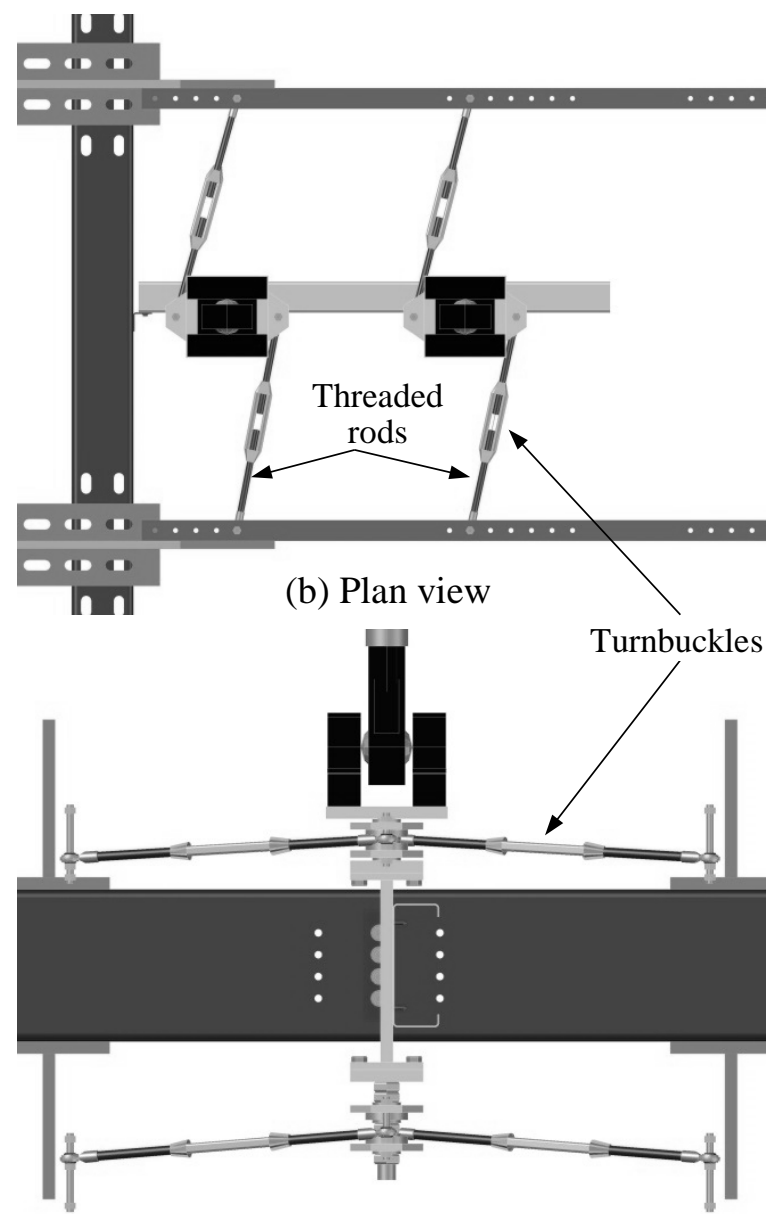

(d) Elevation view - side

Figure 8: Elevation, plan and 3D views of the restraining system. 


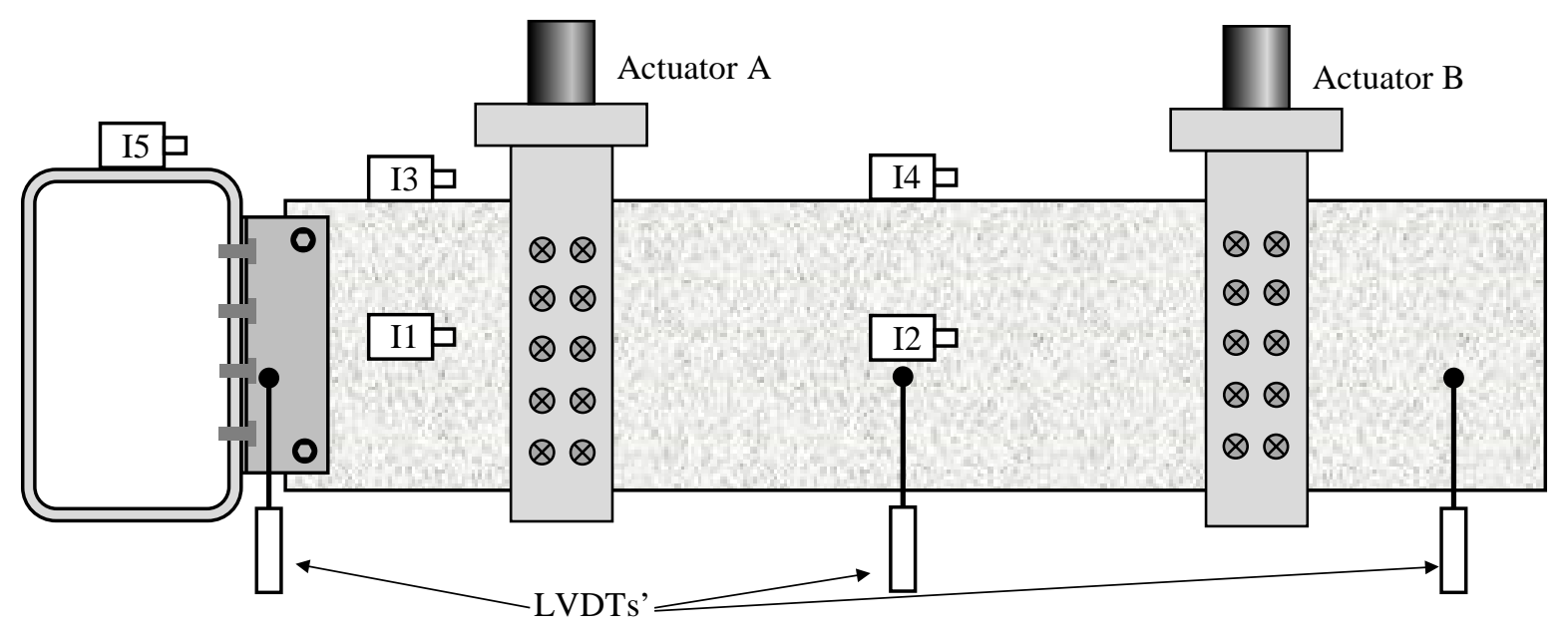

Figure 9: Diagram of locations of transducers and inclinometers. 

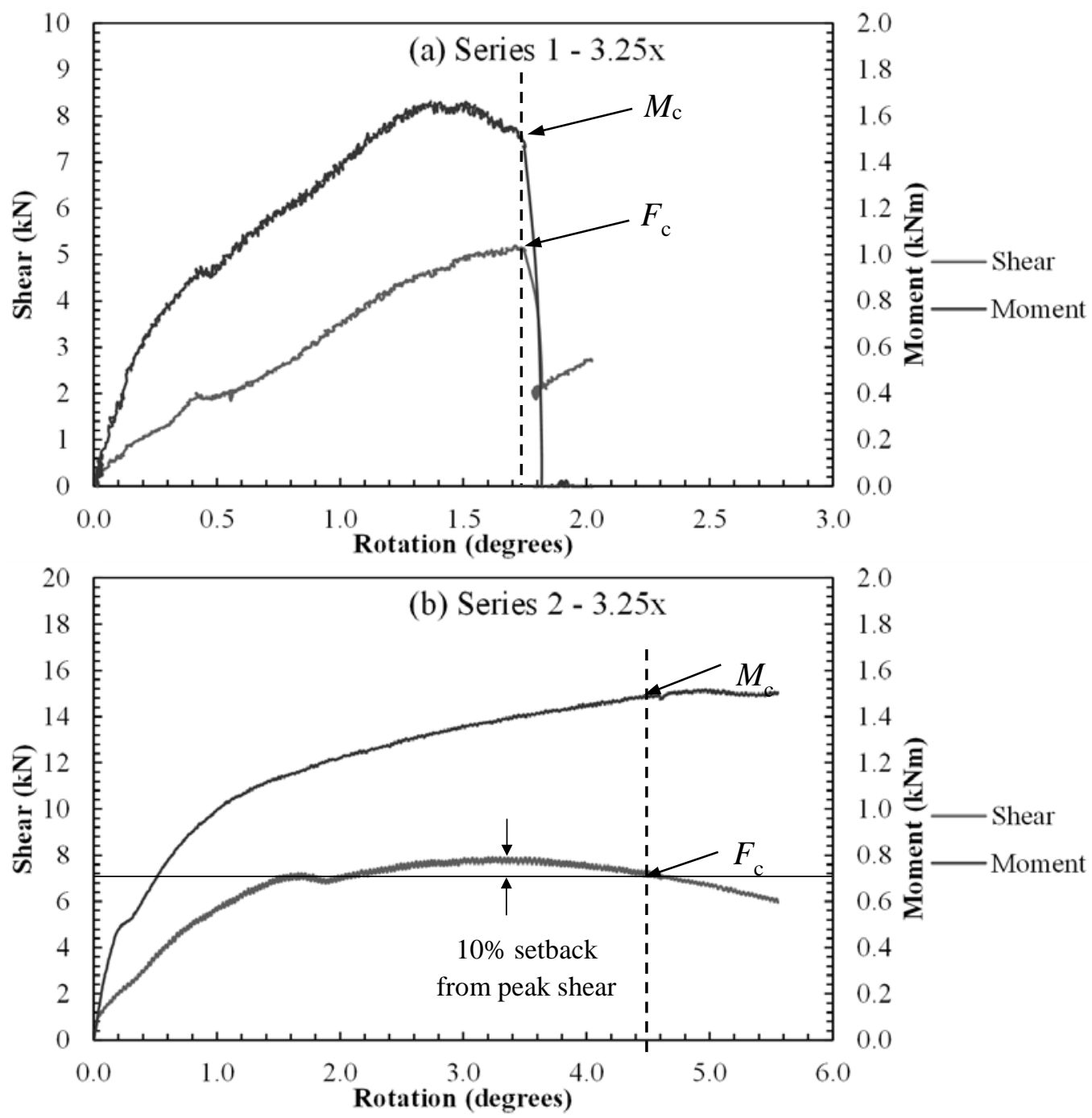

Figure 10: Shear and moment at failure for different behaviour. 

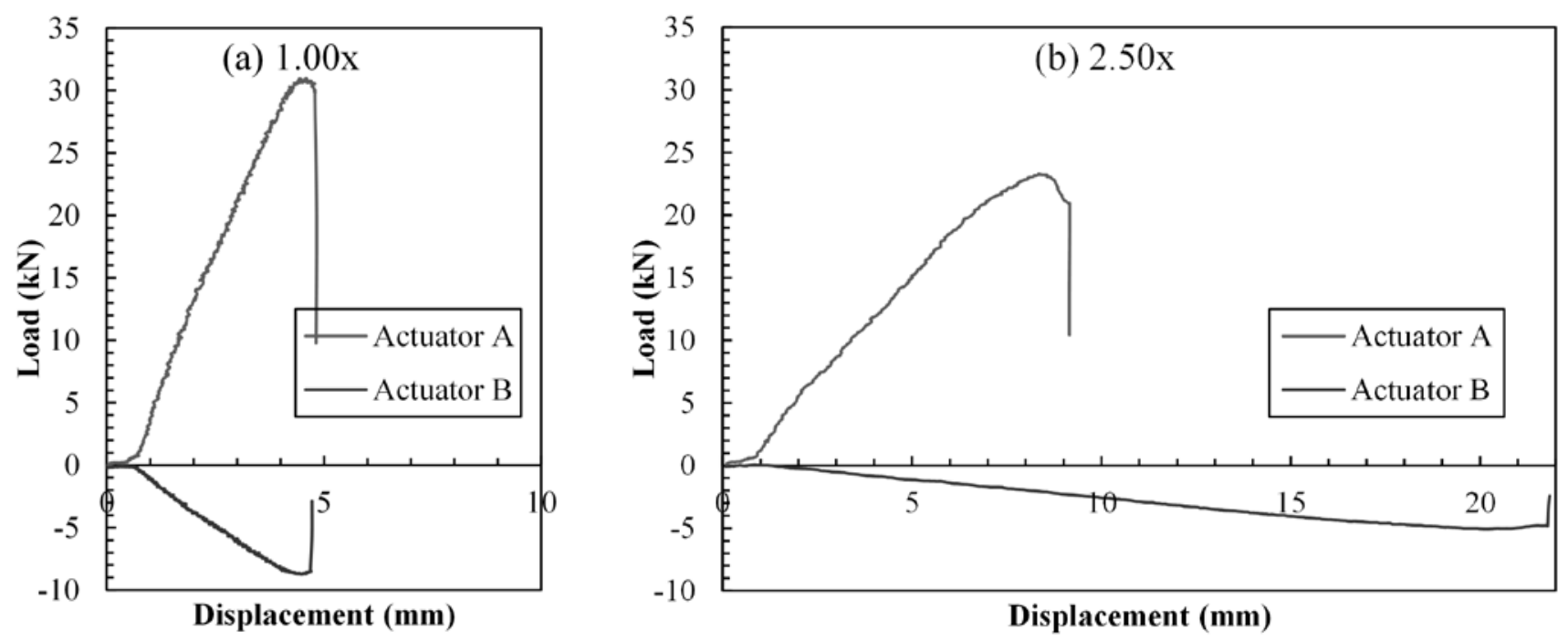

Figure 11: Force and displacement of two actuators for the $R R$ of (a) 1.00x and (b) 2.50x in Series 1. 

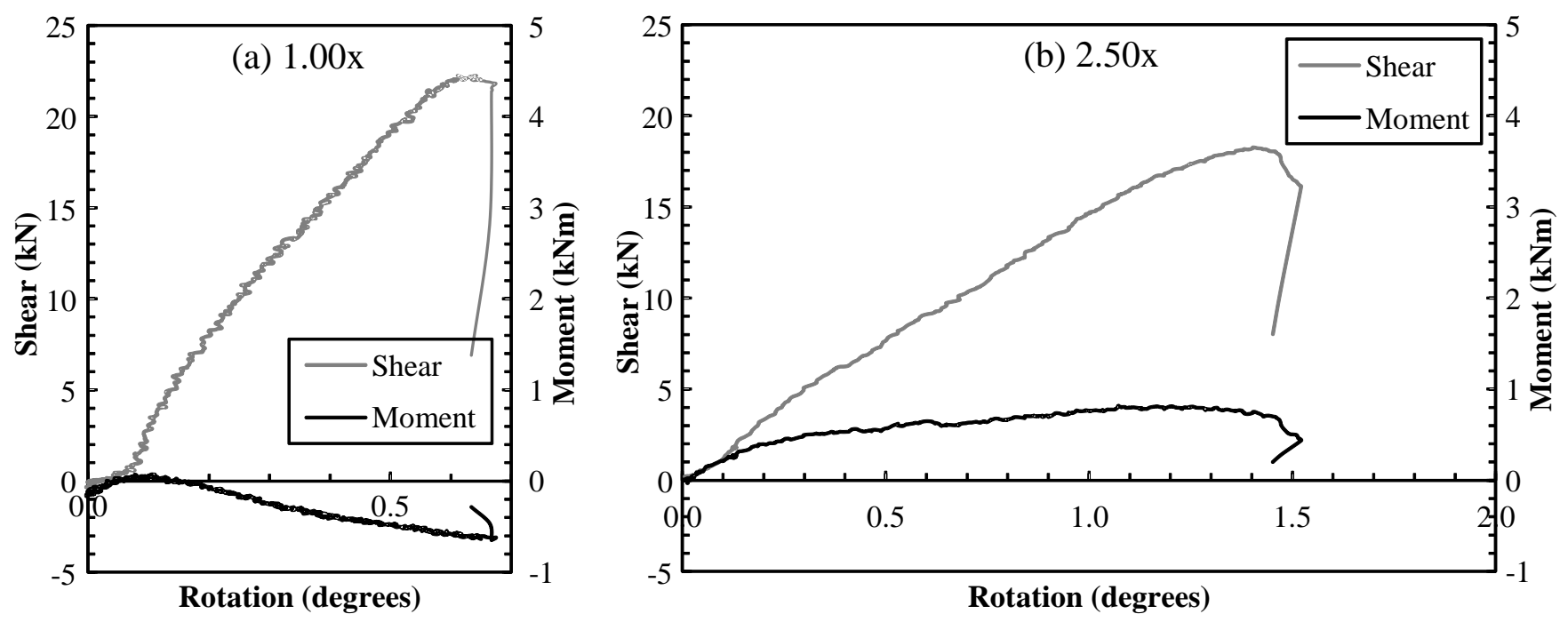

Figure 12: Shear and moment versus rotation of the channel for the $R R$ of

(a) $1.00 \mathrm{x}$ and (b) 2.50x in Series 1. 


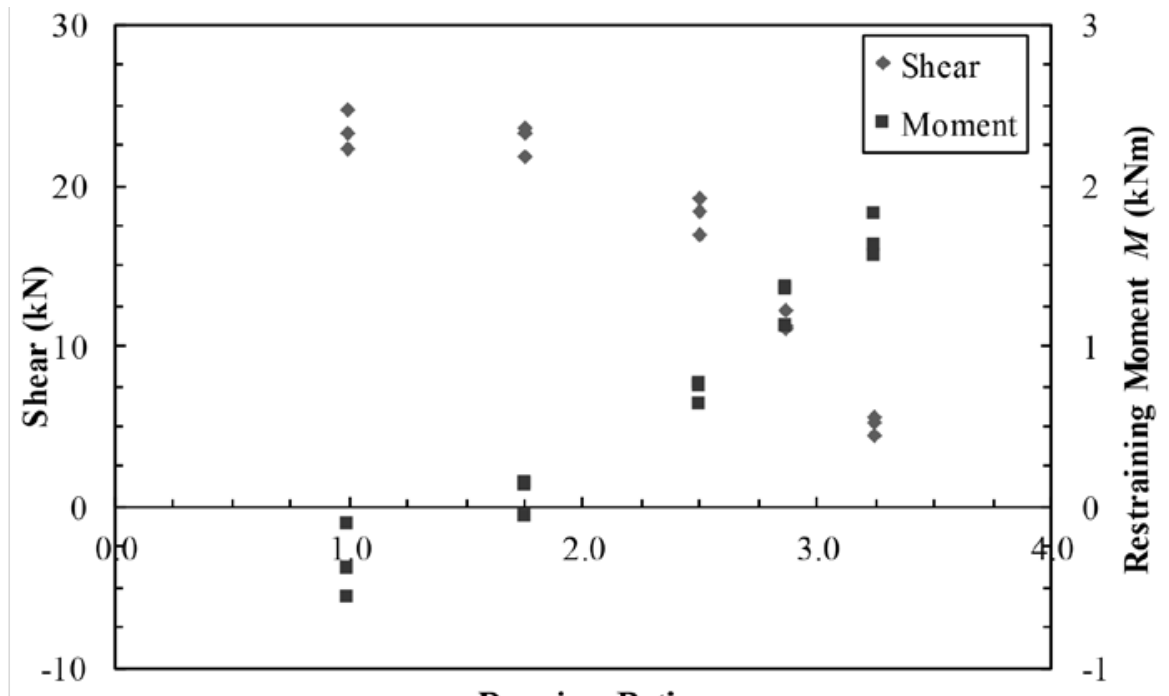

Running Ratio

Figure 13: Ultimate shear and moment for various running ratios from Series 1. 


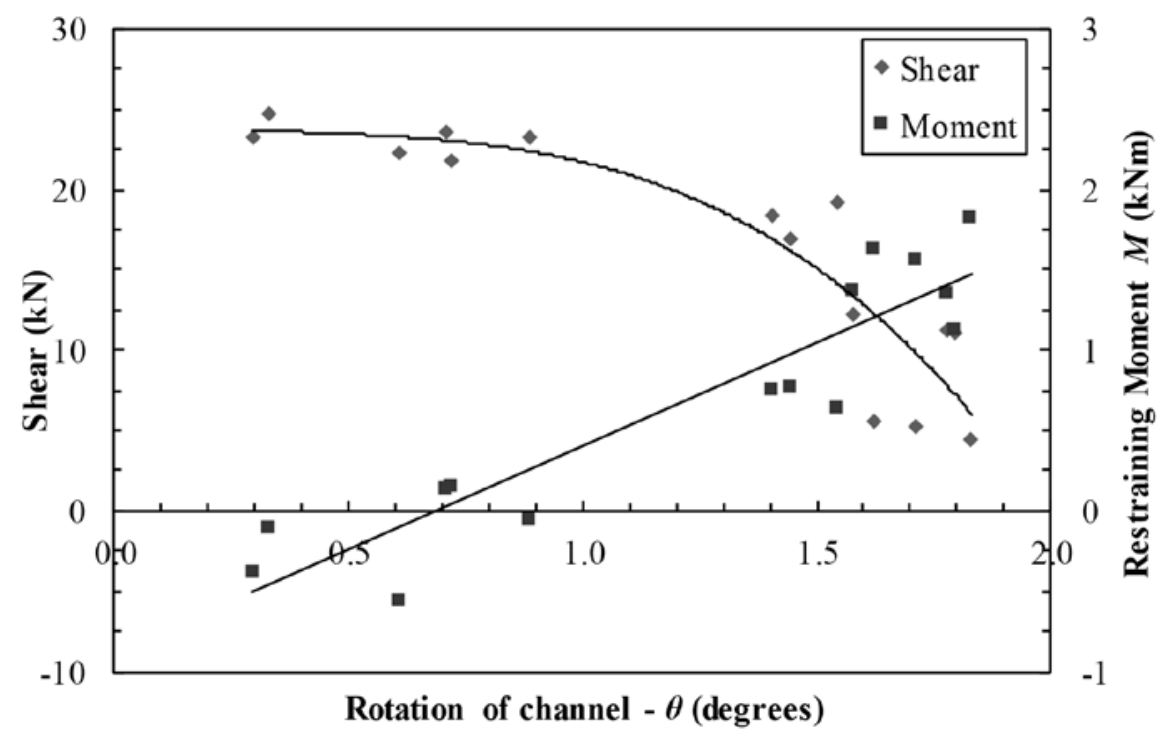

Figure 14: Ultimate shear and moment versus rotation at failure from Series 1. 

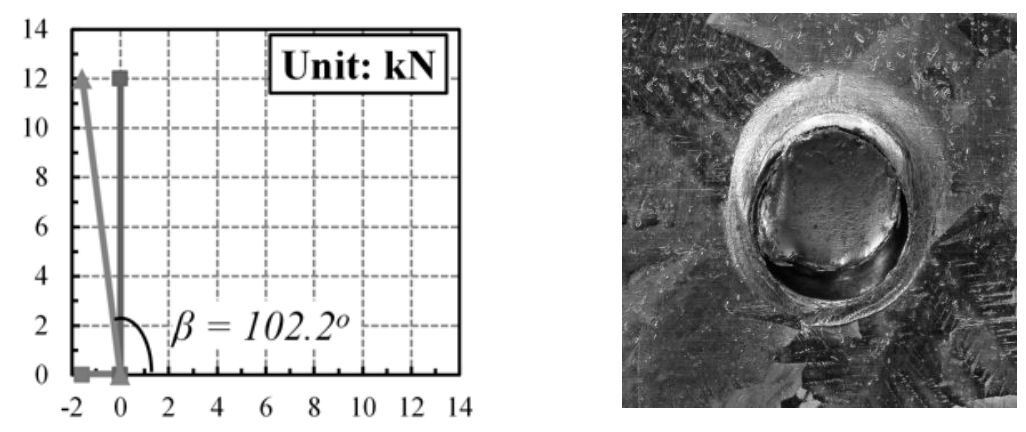

$1.00 x$
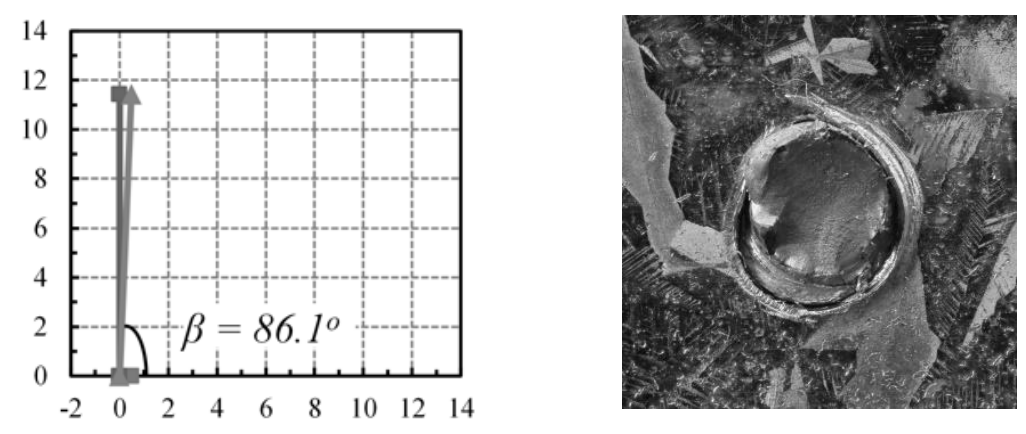

$1.75 x$
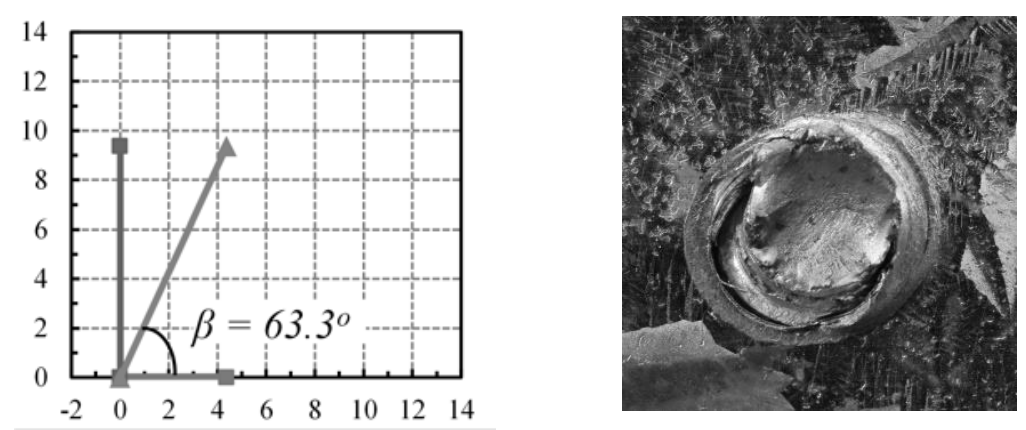

$2.50 \mathrm{x}$
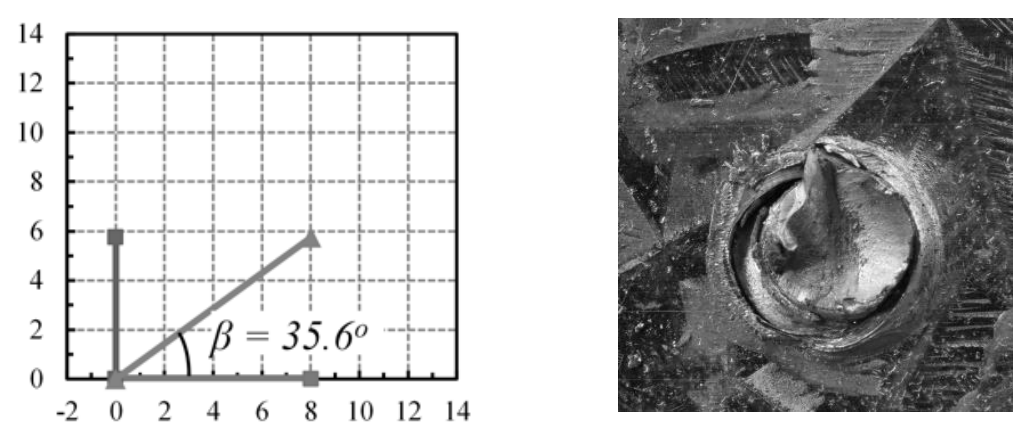

$2.875 x$
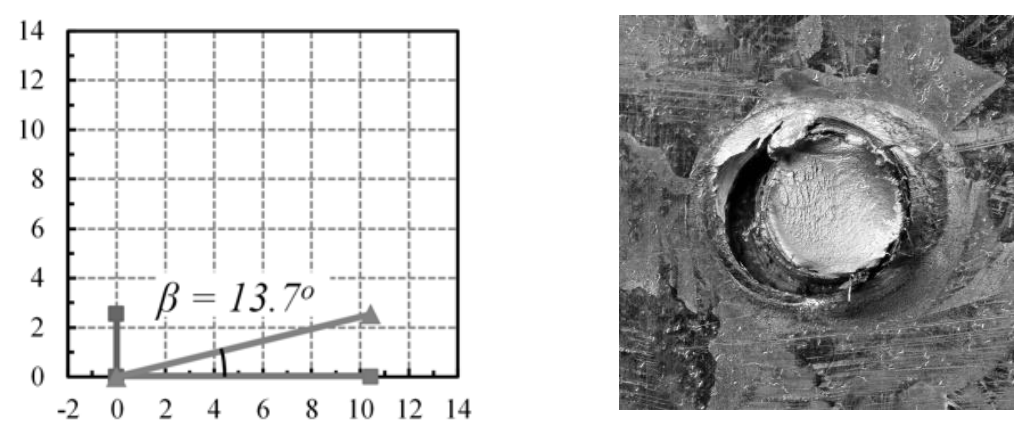

$3.25 x$

Figure 15: Screw bearing forces and directions of the bottom screws in Series 1. 


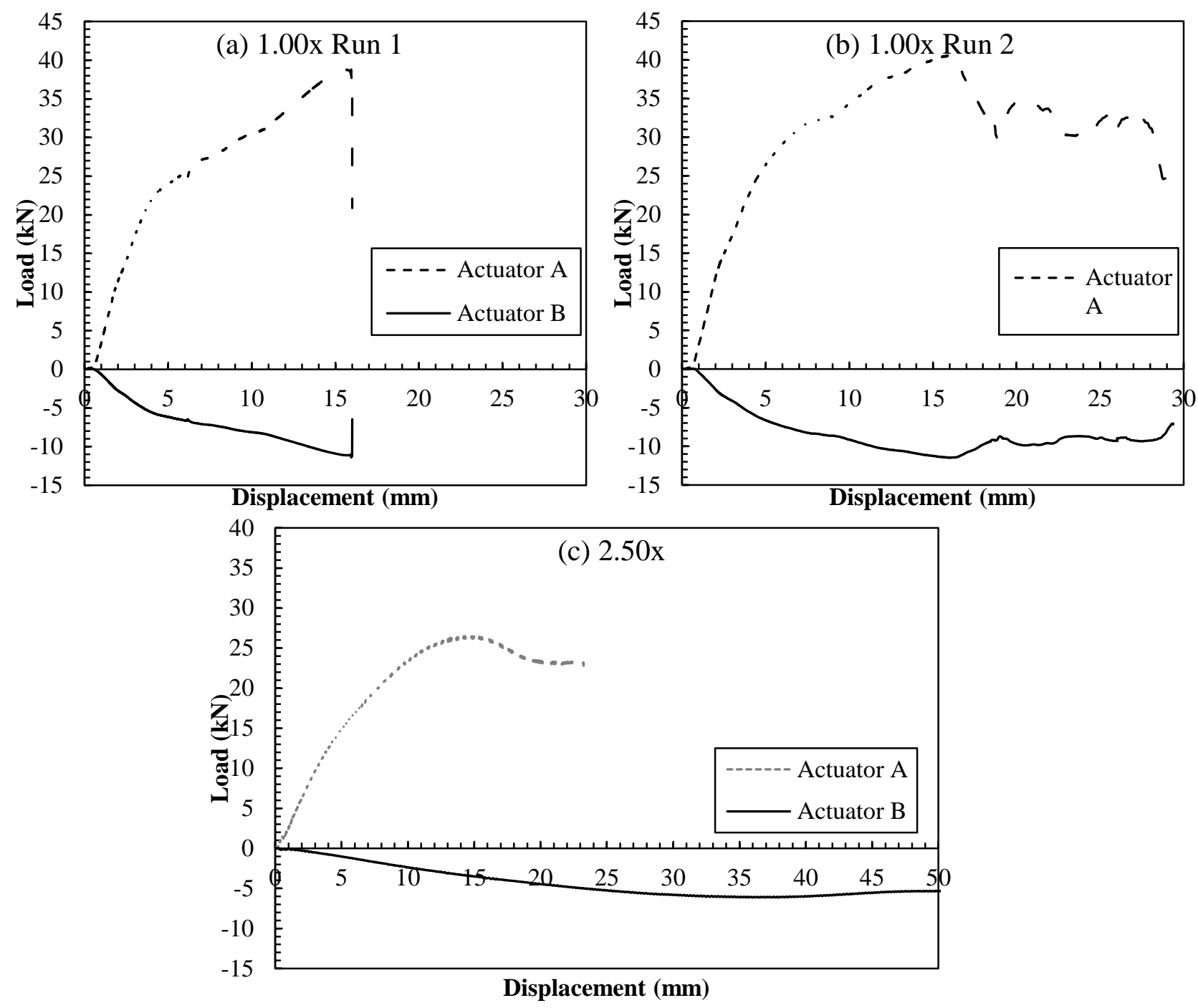

Figure 16: Force and displacement of two actuators for the $R R$ of (a) 1.00x Run 1, (b) 1.00x Run 2 and (c) 2.50x. 


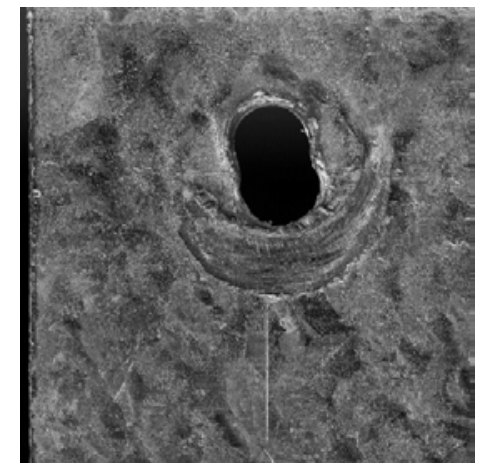

(a)

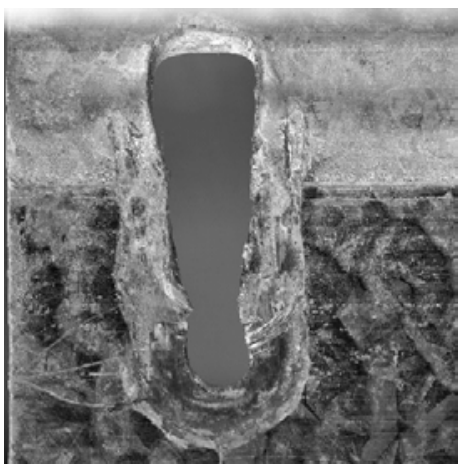

(b)

Figure 17: Bearing of the top screw in 1.00x tests Run 1(a) and Run 2(b). 


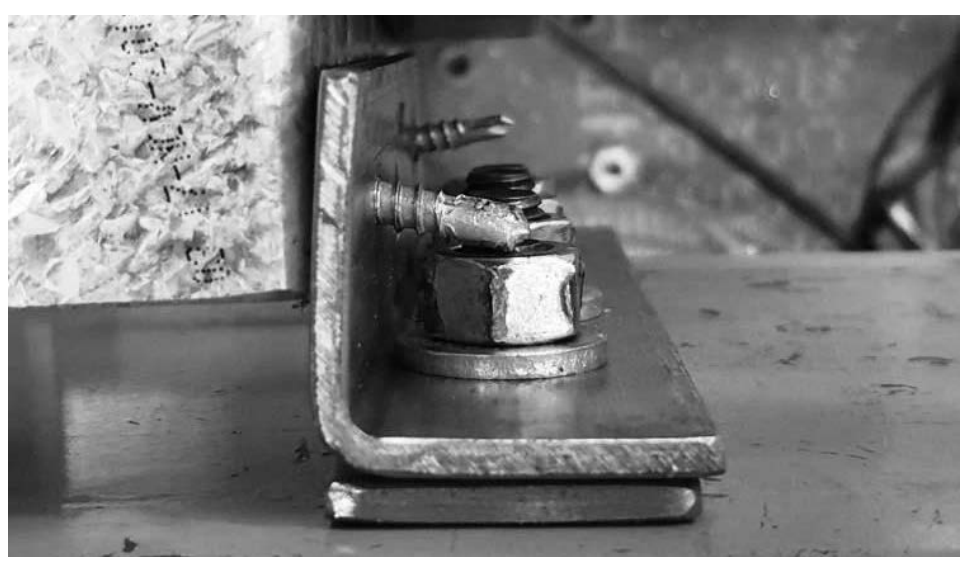

Figure 18: Tilting of the screws in horizontal direction for $R R=3.25 \mathrm{x}$ in Series 2 . 

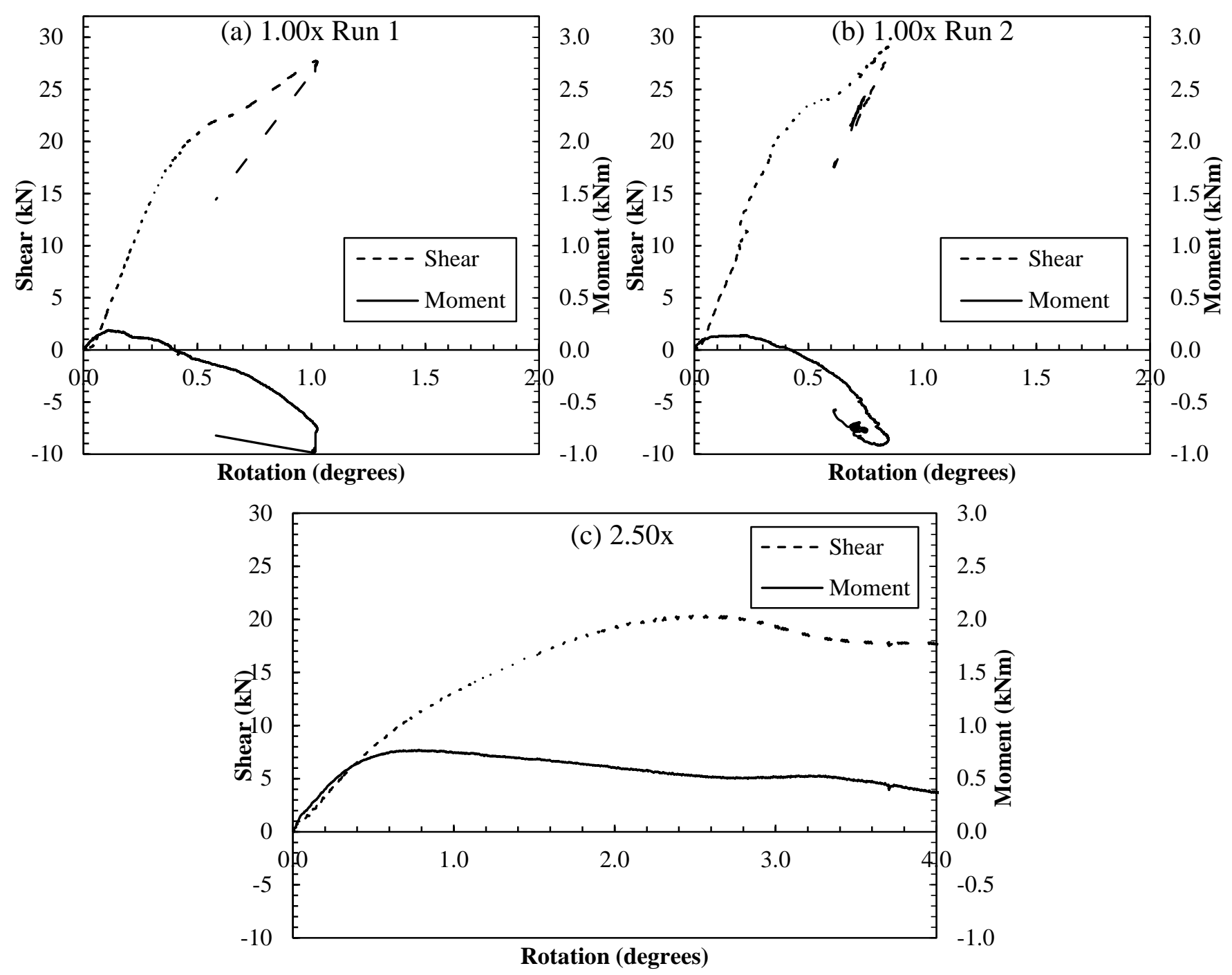

Figure 19: Shear and moment versus rotation of the channel for the running ratios of (a) 1.00x Run 1, (b) 1.00x Run 2 and (c) 2.50x. 


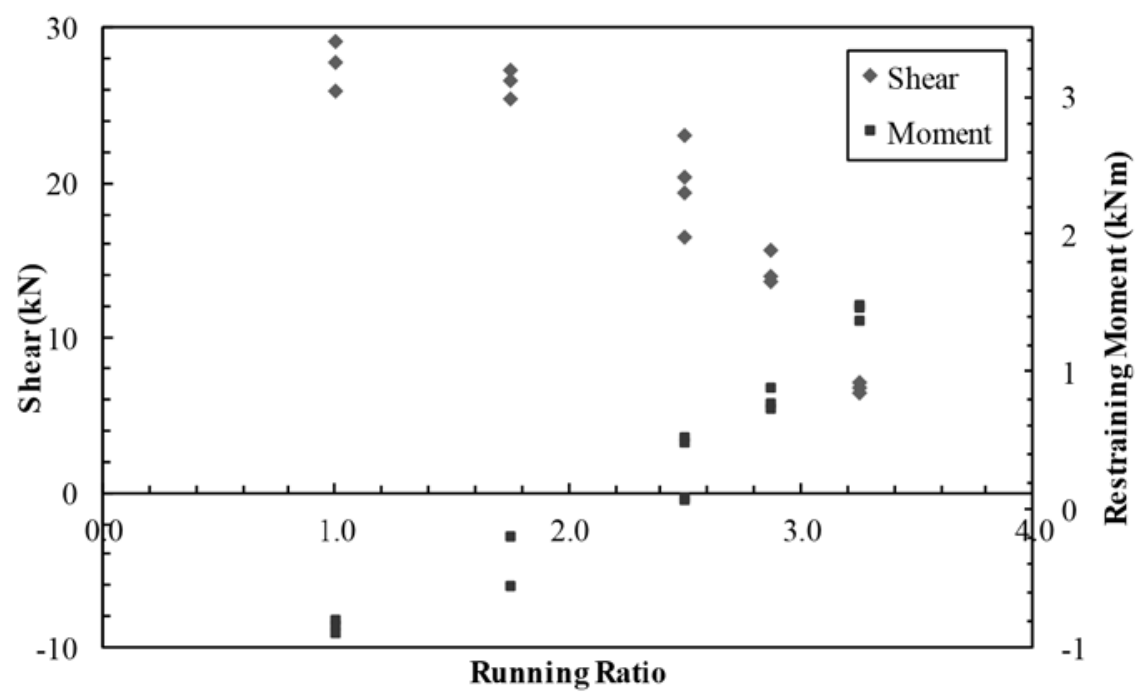

Figure 20: Ultimate shear and moment for various running ratios from Series 2. 


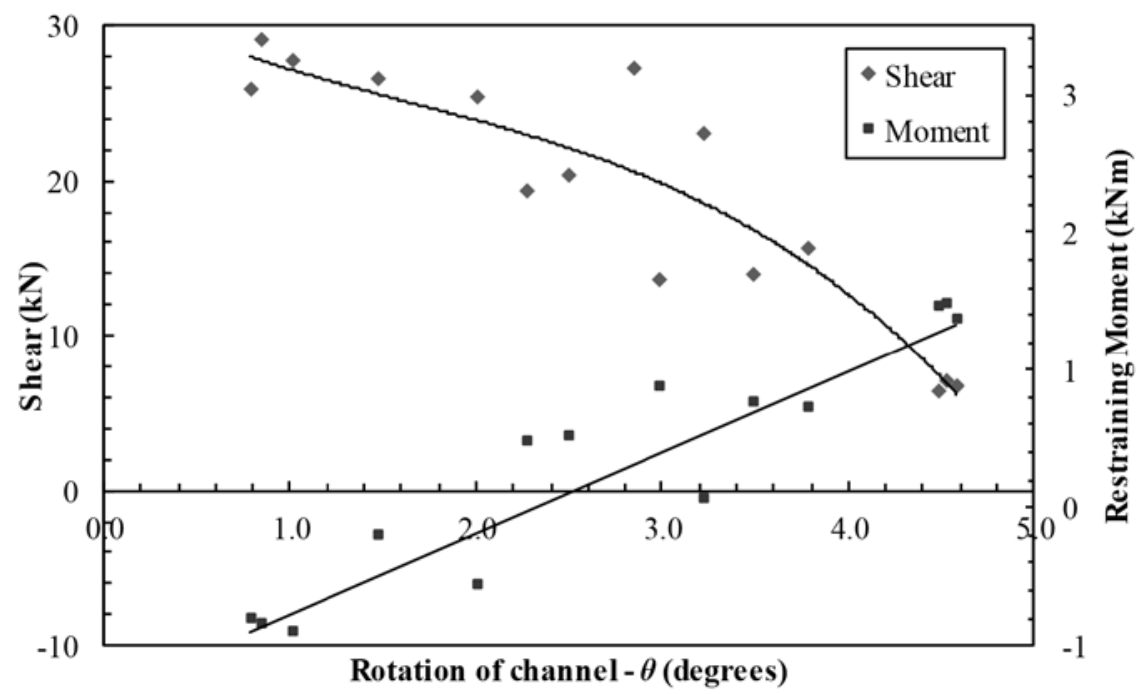

Figure 21: Ultimate shear and moment versus rotation at failure from Series 2. 

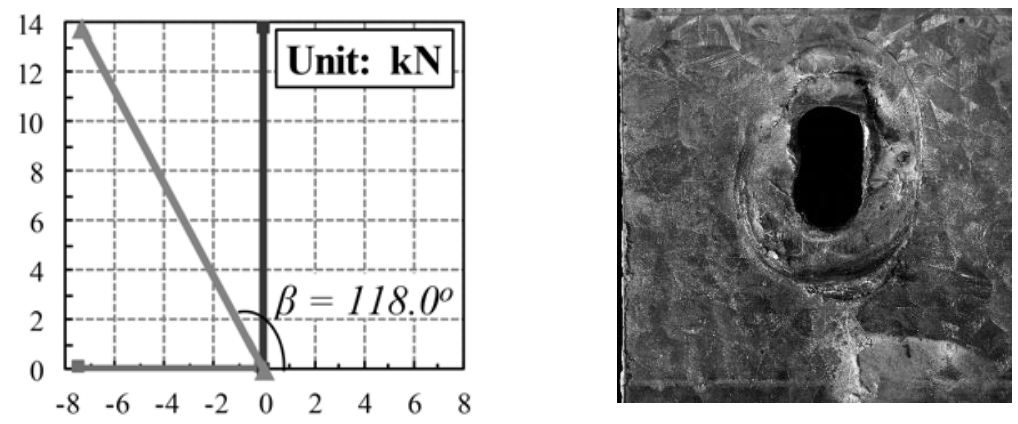

$1.00 \mathrm{x}$
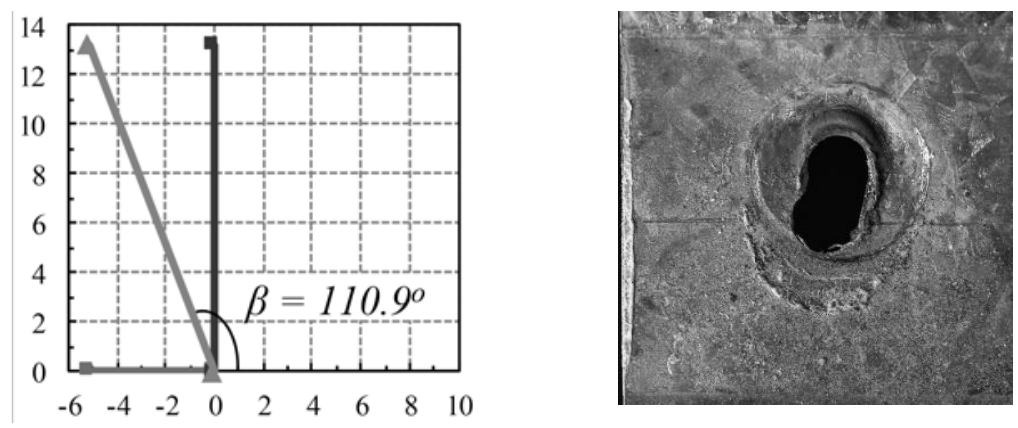

$1.75 \mathrm{x}$
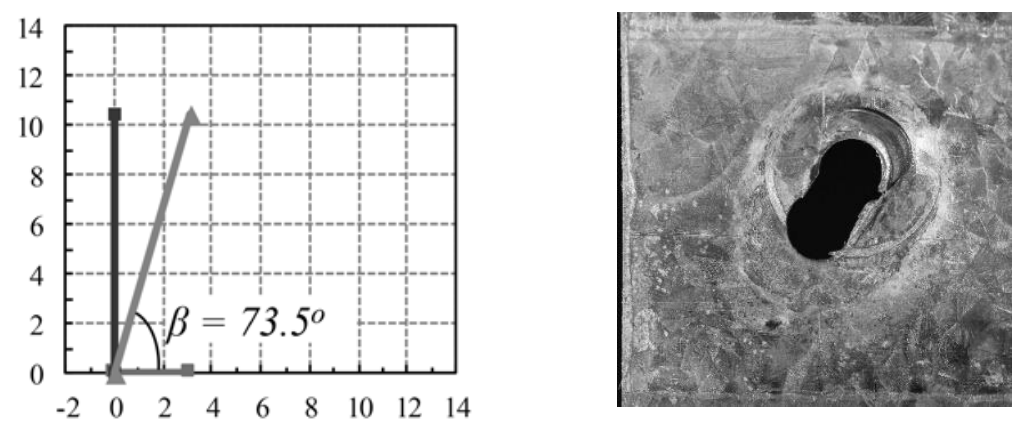

$2.50 \mathrm{x}$
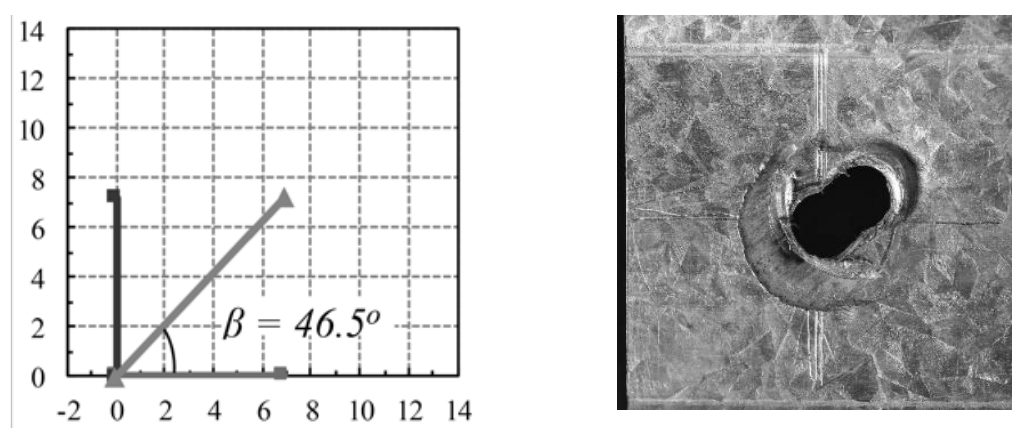

$2.875 x$
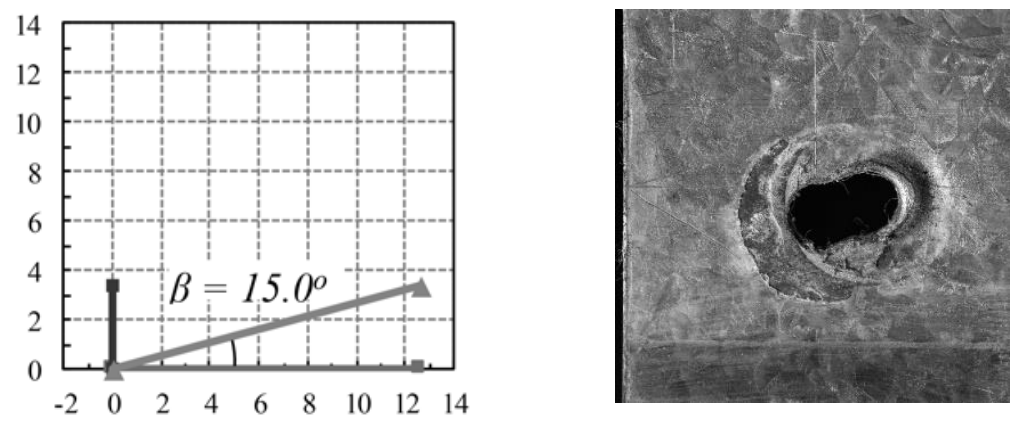

$3.25 x$

Figure 22: Screw bearing forces and directions of the bottom screws in Series 2. 


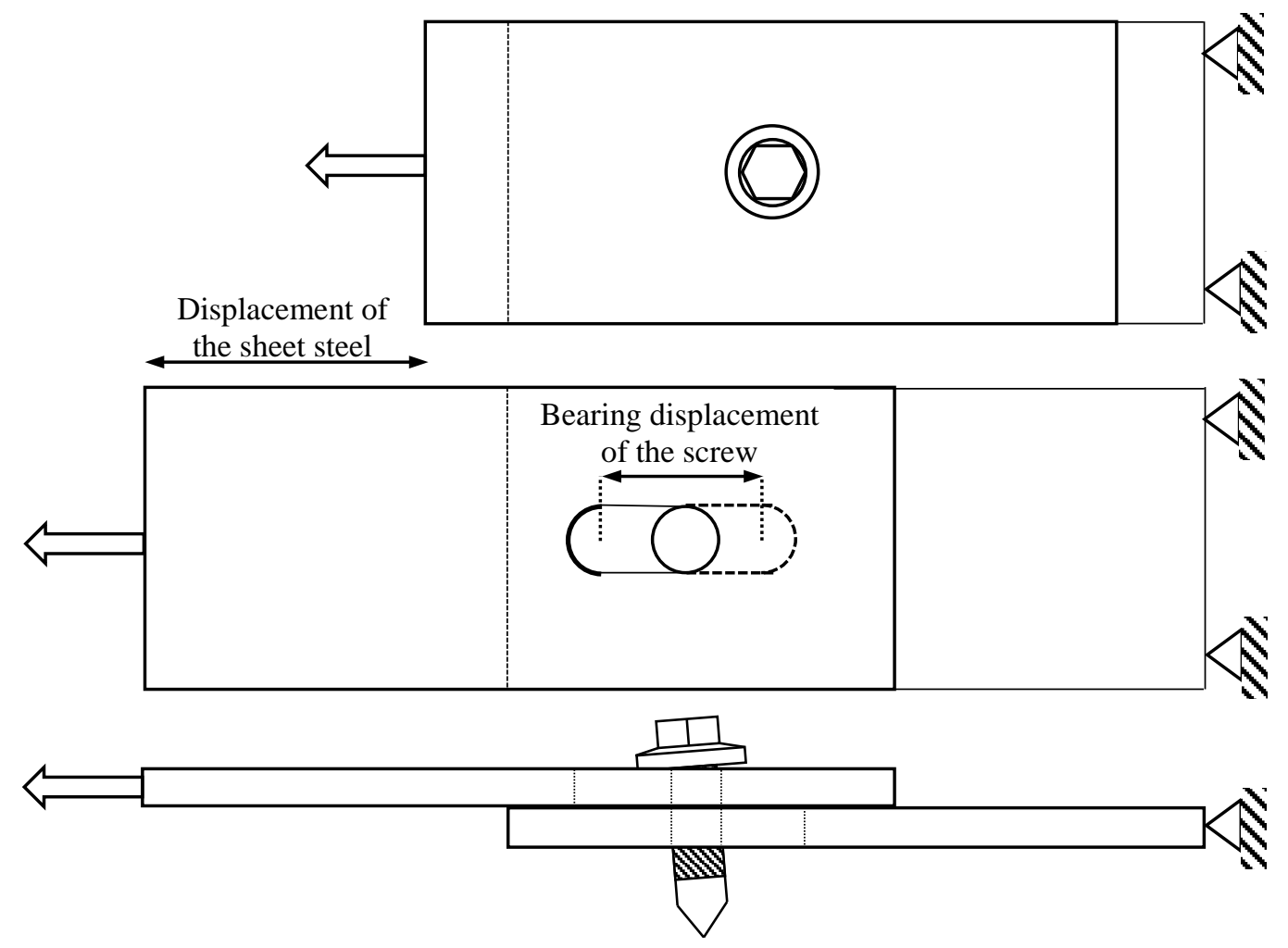

Figure 23: Displacement of a screw in bearing. 

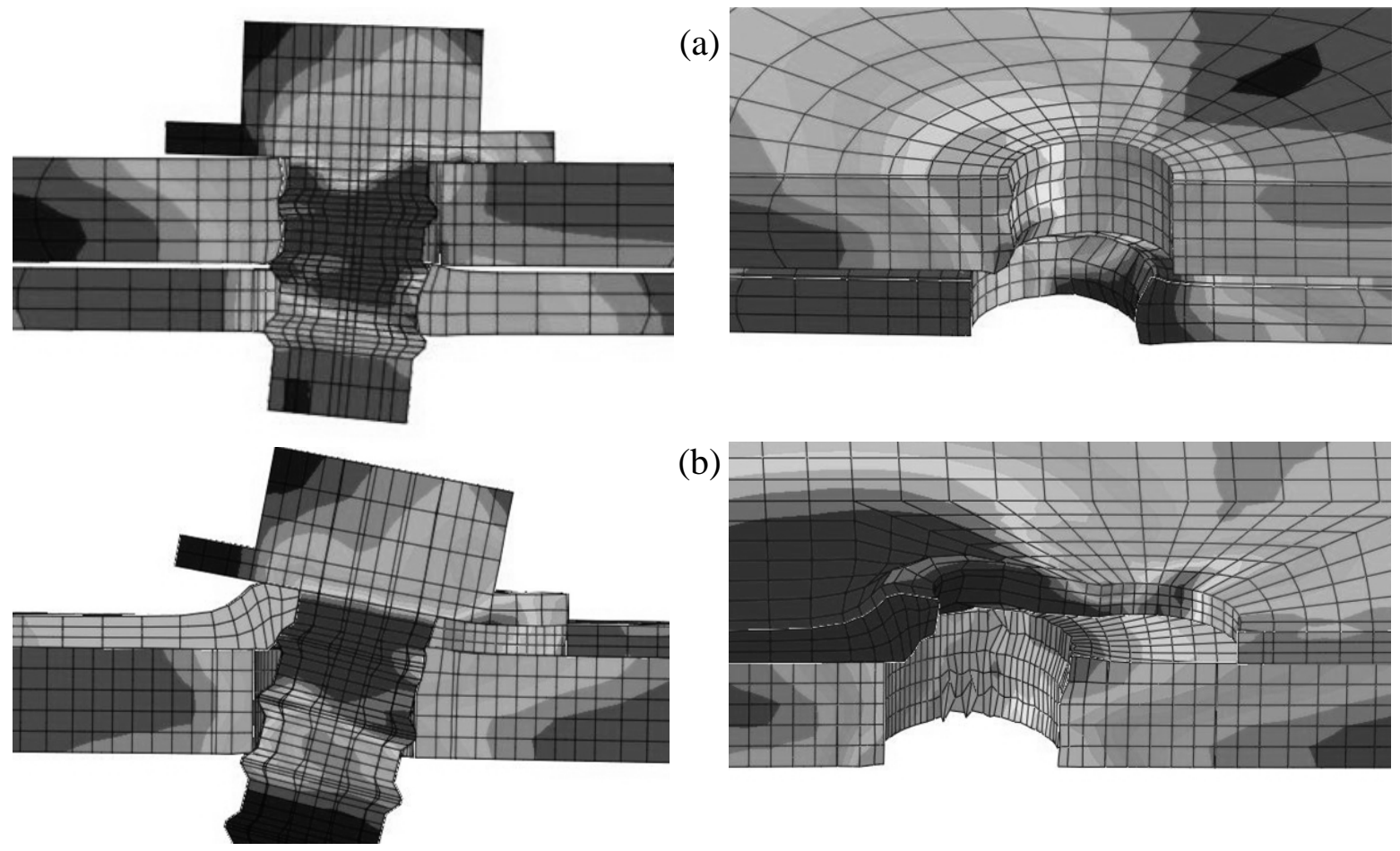

(b)

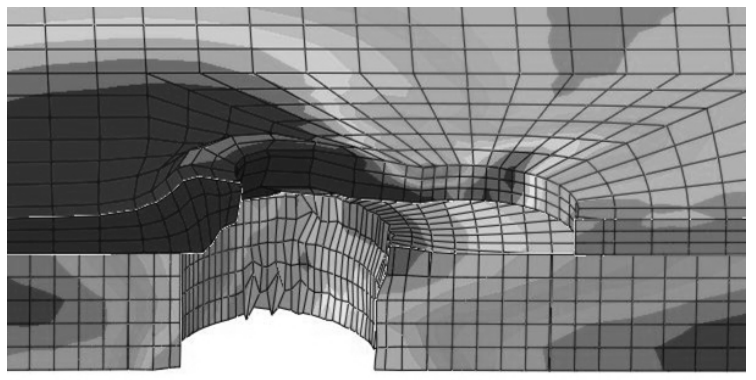

Figure 24: Displacement of the hole during (a) screw shear failure and (b) bearing and tilting failure. 

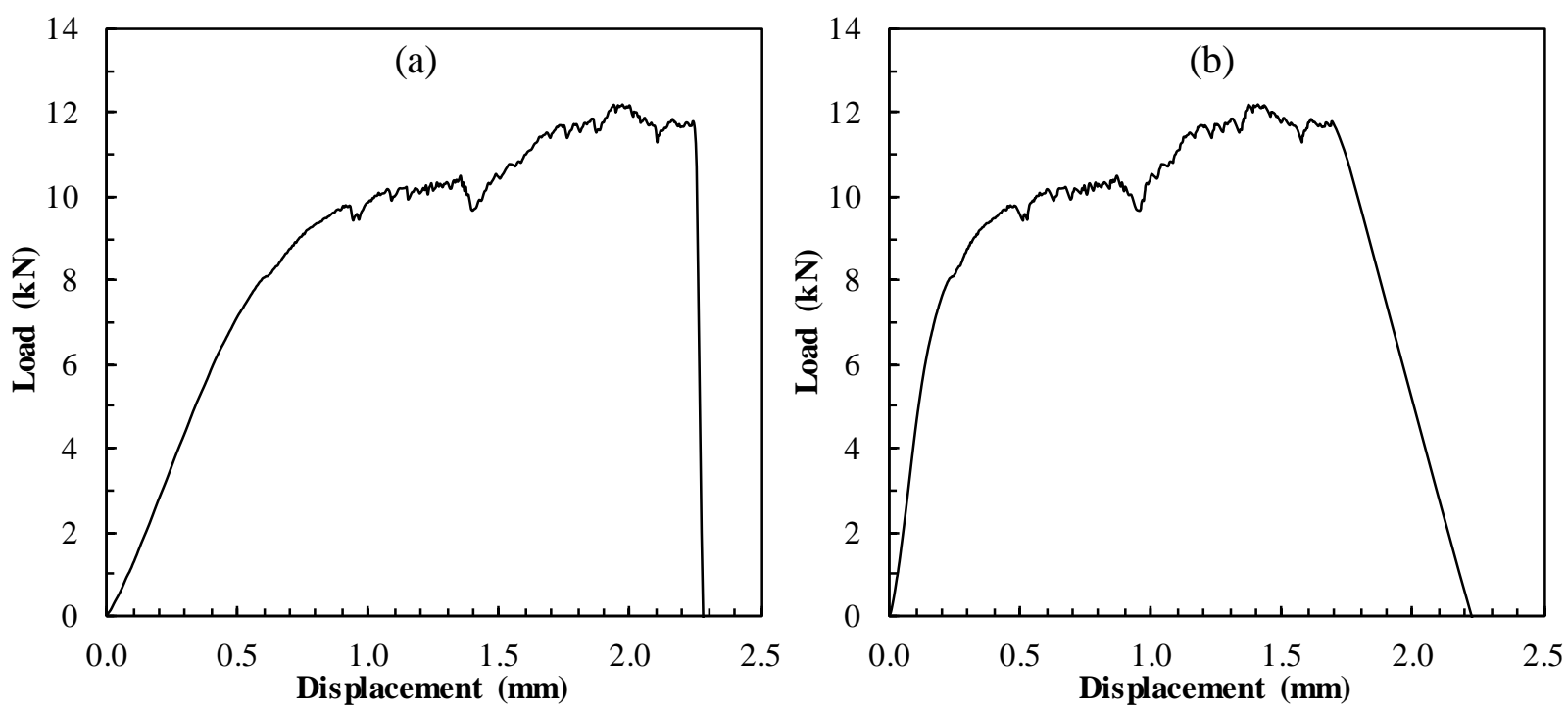

Figure 25: FE results for Series 1: (a) displacement at two ends of the connection and (b) bearing displacement at the connector. 

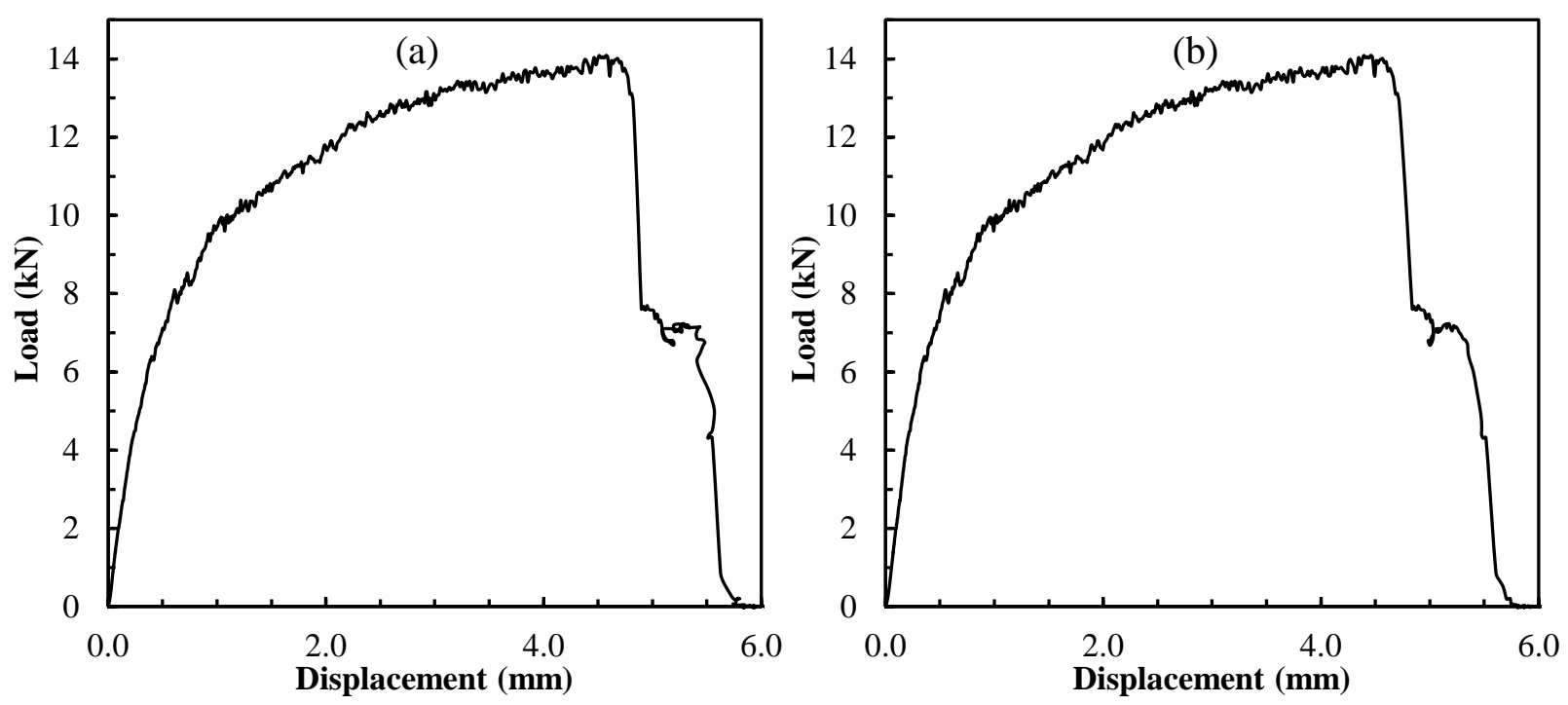

Figure 26: FE results for Series 2: (a) displacement at two ends of the connection and (b) bearing displacement at the connector. 


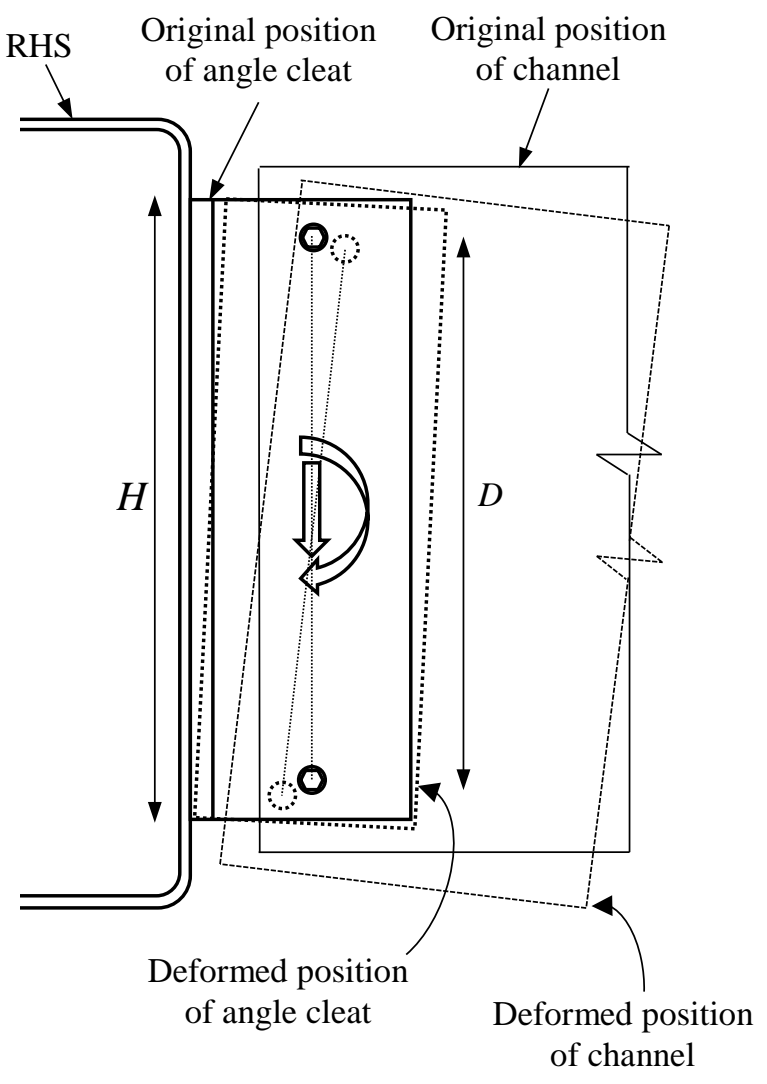

(a)

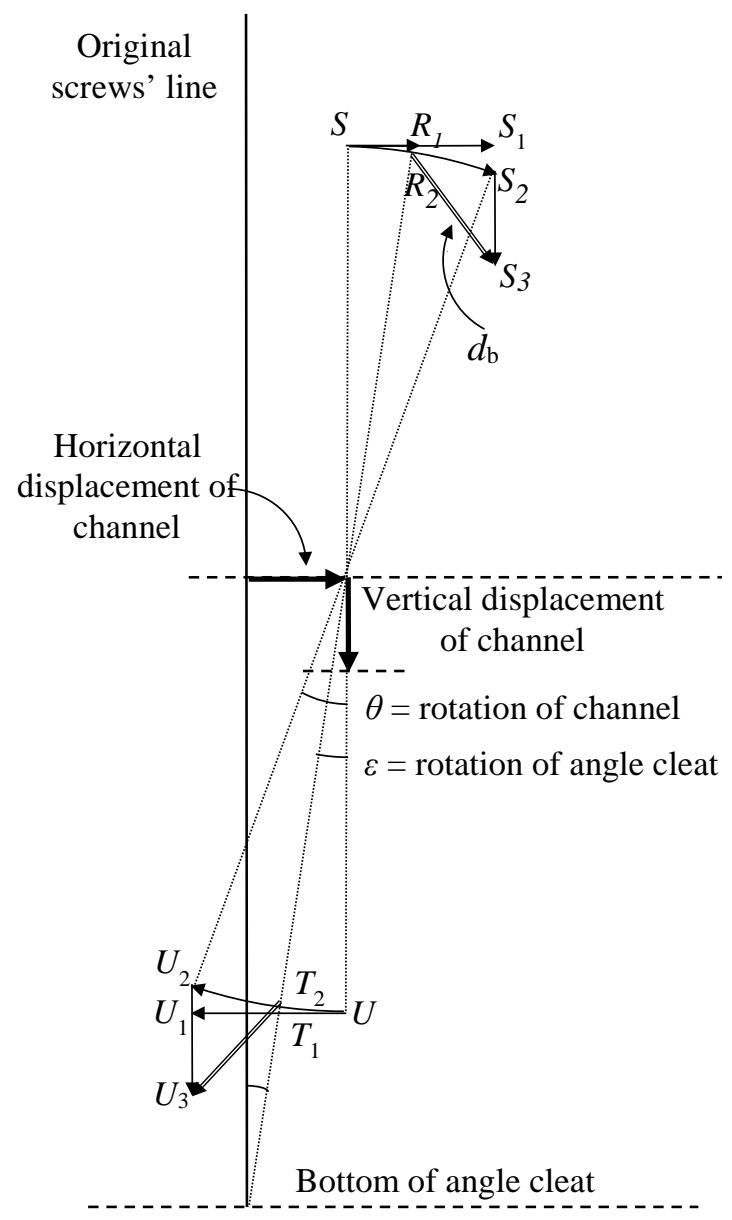

(b)

Figure 27: (a) Rotation and vertical movement of the channel and the AC and (b) bearing displacement of the top screw. 


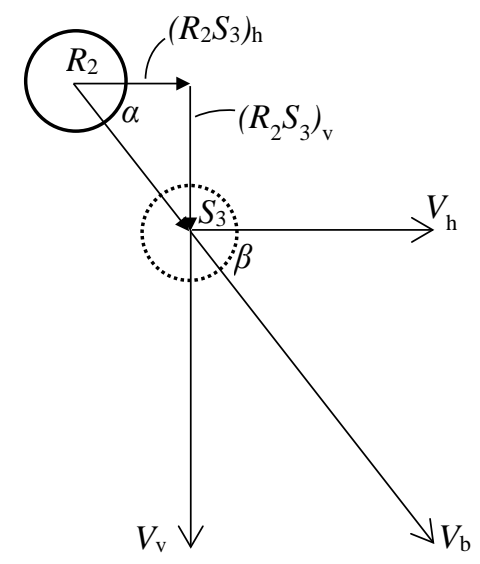

Figure 28: Bearing displacement and bearing force of the top screw. 

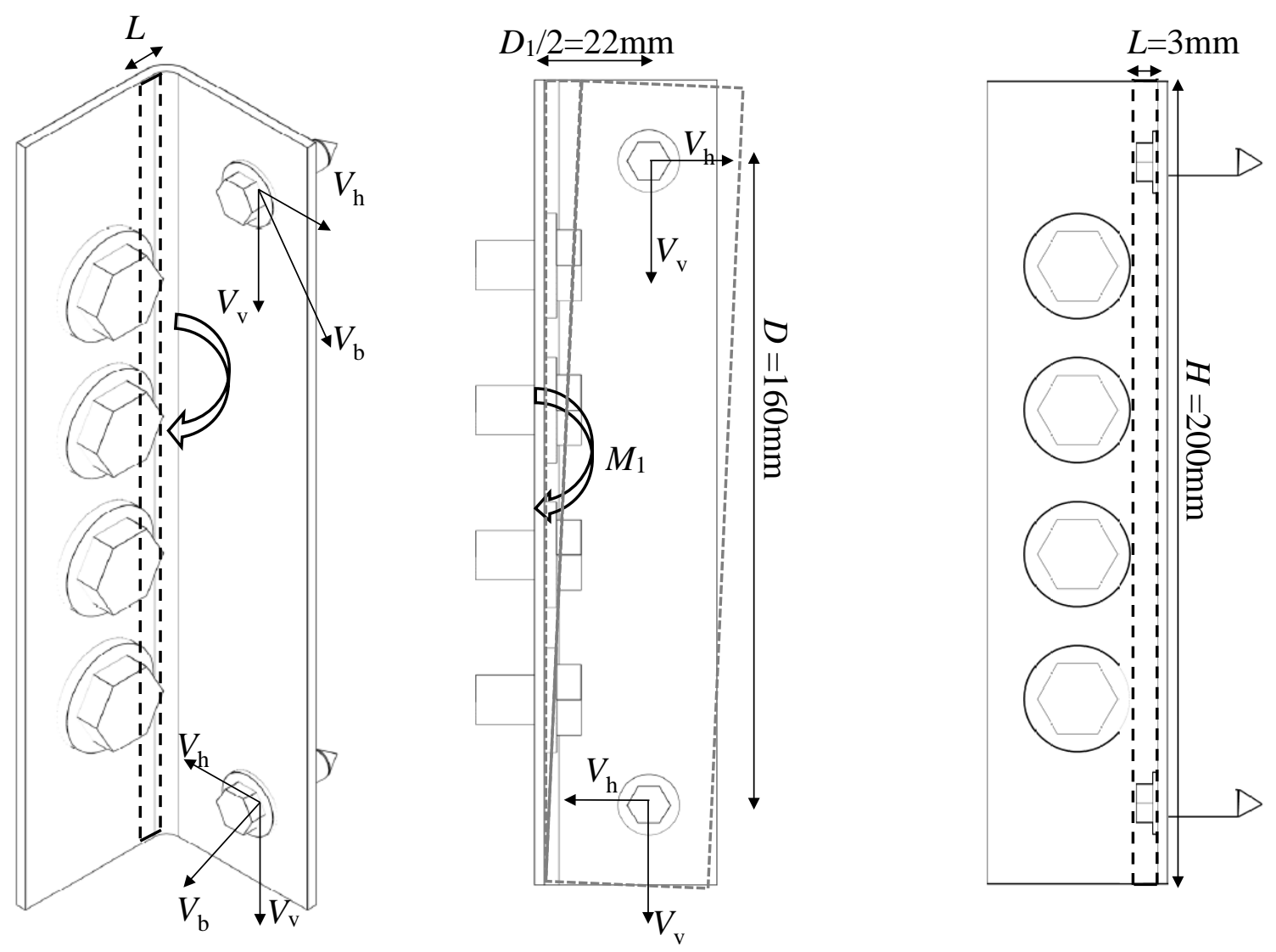

Figure 29: Moment and rotation on the AC. 

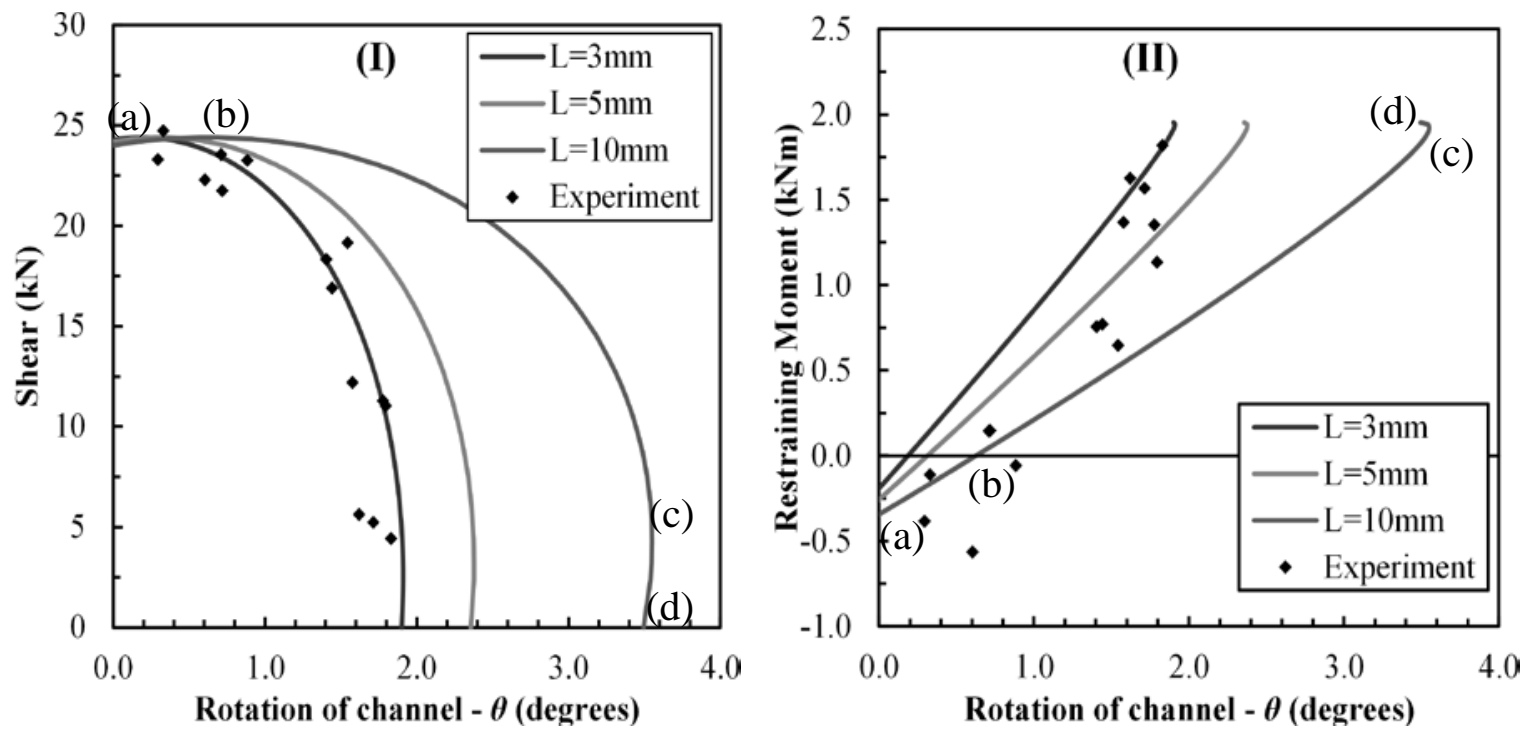

Figure 30: Comparison between experimental and theoretical results using twisting theory for (I) shear force versus rotation at failure; and (II) moment versus rotation at failure. 

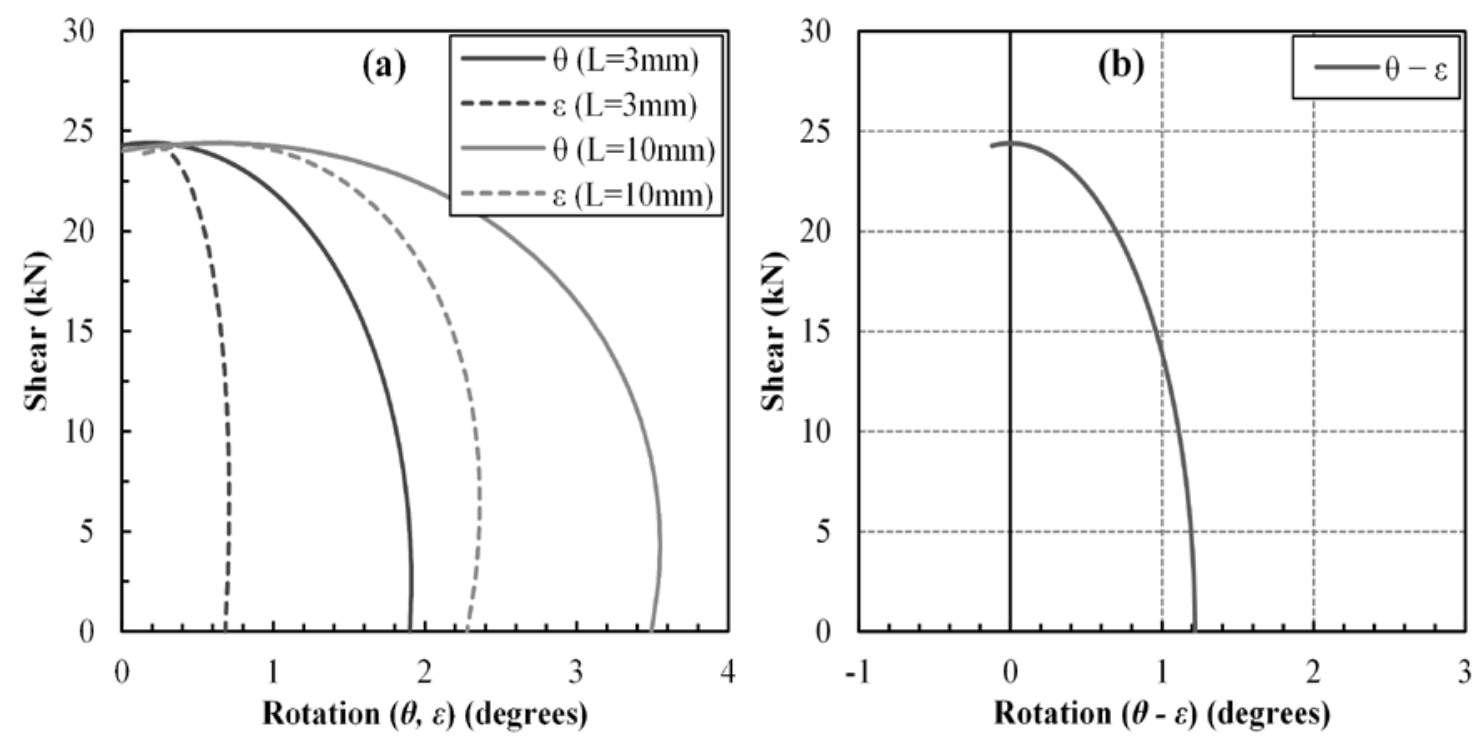

Figure 31: Shear versus (a) rotation of the angle cleat $(\varepsilon)$ and the C-channel $(\theta)$; and (b) relative rotation of the C-channel compared with the angle cleat. 


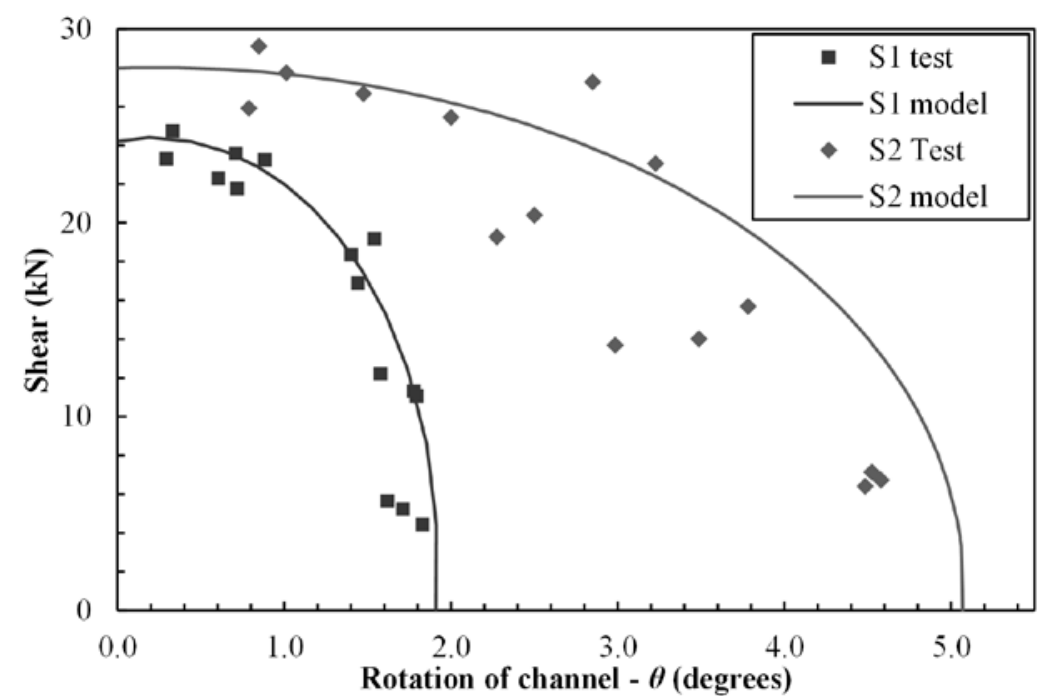

Figure 32: Shear versus rotation at failure for the two test series. 


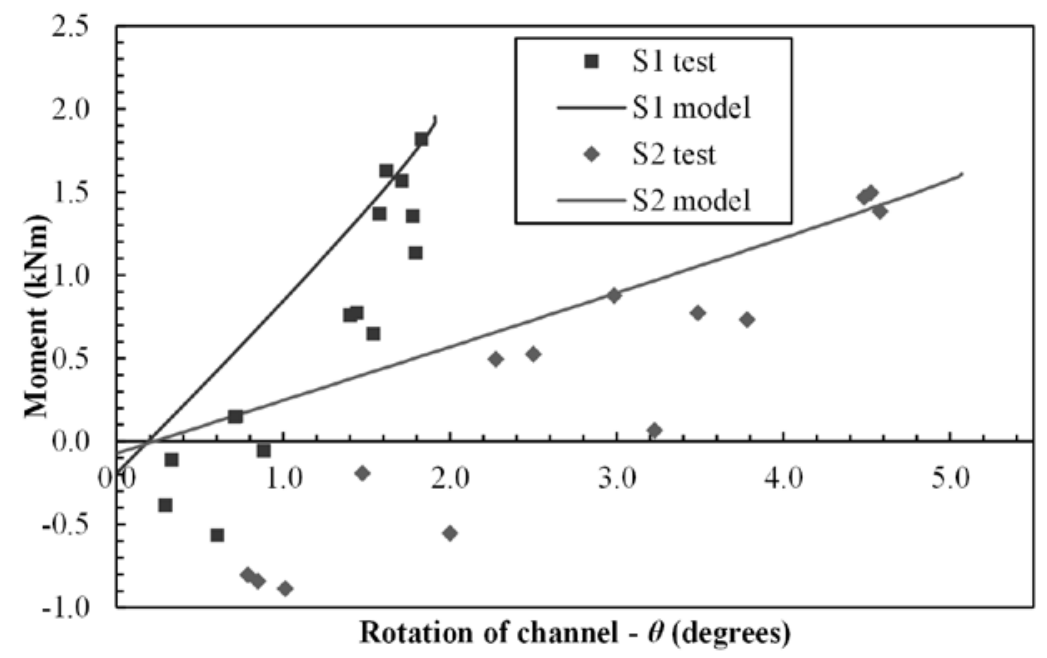

Figure 33: Moment versus rotation at failure for the two test series. 


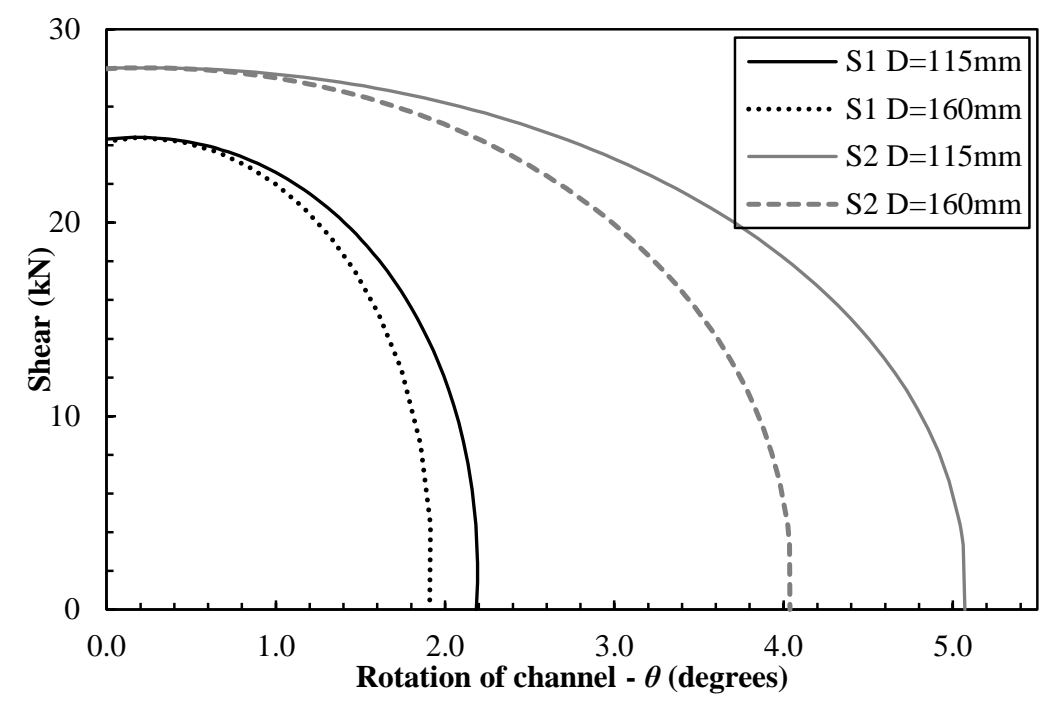

Figure 34: Study of the effect of screw spacing on rotational ductility. 
Table 1: Measured material properties of the cold-formed steels.

\begin{tabular}{cccc}
\hline Steel & thickness $(\mathrm{mm})$ & $f_{\mathrm{y}}(\mathrm{MPa})$ & $f_{\mathrm{u}}(\mathrm{MPa})$ \\
\hline G450 & 2.4 & 531 & 563 \\
G500 & 1.2 & 601 & 619 \\
\hline
\end{tabular}


Table 2: Experimental results at failure of the screws for Series 1.

\begin{tabular}{|c|c|c|c|c|c|c|c|c|}
\hline \multirow[b]{2}{*}{$\begin{array}{c}\text { Running } \\
\text { Ratio } \\
R R\end{array}$} & \multirow[b]{2}{*}{$\begin{array}{c}\text { Rotation of } \\
\text { channel at } \\
\text { screw failure } \\
\theta \text { (degrees) }\end{array}$} & \multirow[b]{2}{*}{$\begin{array}{c}\text { Actuator } \\
\text { A force } \\
F_{\mathrm{A}}(\mathrm{kN})\end{array}$} & \multirow[b]{2}{*}{$\begin{array}{c}\text { Actuator } \\
\text { B force } \\
F_{\mathrm{B}}(\mathrm{kN})\end{array}$} & \multirow[b]{2}{*}{$\begin{array}{c}\text { Shear at } \\
\text { connection } \\
F_{\mathrm{c}}(\mathrm{kN})\end{array}$} & \multirow[b]{2}{*}{$\begin{array}{l}\text { Moment at } \\
\text { connection } \\
M_{\mathrm{c}}(\mathrm{kNm})\end{array}$} & \multicolumn{3}{|c|}{ Bearing force on each screw } \\
\hline & & & & & & $\begin{array}{c}\text { Horizontal } \\
\text { force } \\
V_{\mathrm{h}}(\mathrm{kN})\end{array}$ & $\begin{array}{c}\text { Vertical } \\
\text { force } \\
V_{\mathrm{v}}(\mathrm{kN})\end{array}$ & $\begin{array}{c}\text { Total } \\
\text { vectorial } \\
\text { force } V_{\mathrm{b}} \\
(\mathrm{kN})\end{array}$ \\
\hline 1.00 & 0.304 & 31.97 & -8.71 & 23.27 & -0.396 & -2.48 & 11.63 & 11.89 \\
\hline 1.00 & 0.334 & 33.43 & -8.72 & 24.71 & -0.116 & -0.73 & 12.35 & 12.38 \\
\hline 1.00 & 0.642 & 30.95 & -8.70 & 22.25 & -0.595 & -3.72 & 11.13 & 11.73 \\
\hline 1.75 & 0.888 & 31.36 & -8.17 & 23.19 & -0.100 & -0.63 & 11.59 & 11.61 \\
\hline 1.75 & 0.714 & 31.43 & -7.89 & 23.54 & 0.133 & 0.83 & 11.77 & 11.80 \\
\hline 1.75 & 0.713 & 28.95 & -7.24 & 21.71 & 0.142 & 0.89 & 10.85 & 10.89 \\
\hline 2.50 & 1.548 & 24.62 & -5.50 & 19.13 & 0.638 & 3.99 & 9.56 & 10.36 \\
\hline 2.50 & 1.403 & 23.27 & -5.00 & 18.27 & 0.751 & 4.69 & 9.13 & 10.27 \\
\hline 2.50 & 1.427 & 21.33 & -4.48 & 16.85 & 0.769 & 4.81 & 8.42 & 9.70 \\
\hline 2.875 & 1.806 & 12.93 & -1.92 & 11.01 & 1.087 & 6.79 & 5.50 & 8.74 \\
\hline 2.875 & 1.785 & 12.81 & -1.54 & 11.27 & 1.358 & 8.49 & 5.63 & 10.19 \\
\hline 2.875 & 1.586 & 14.04 & -1.88 & 12.17 & 1.344 & 8.40 & 6.08 & 10.37 \\
\hline 3.25 & 1.824 & 2.77 & 1.59 & 4.37 & 1.797 & 11.23 & 2.18 & 11.44 \\
\hline 3.25 & 1.714 & 4.31 & 0.88 & 5.19 & 1.547 & 9.67 & 2.60 & 10.01 \\
\hline 3.25 & 1.615 & 4.71 & 0.86 & 5.57 & 1.615 & 10.09 & 2.78 & 10.47 \\
\hline
\end{tabular}


Table 3: Experimental results at bearing and tilting failure for Series 2.

\begin{tabular}{|c|c|c|c|c|c|c|c|c|}
\hline \multirow[b]{2}{*}{$\begin{array}{c}\text { Running } \\
\text { Ratio } \\
R R\end{array}$} & \multirow[b]{2}{*}{$\begin{array}{c}\text { Rotation of } \\
\text { channel at } \\
\text { screw failure } \\
\theta \text { (degrees) }\end{array}$} & \multirow[b]{2}{*}{$\begin{array}{l}\text { Actuator } \\
\text { A force } \\
F_{\text {A }}(\mathrm{kN})\end{array}$} & \multirow[b]{2}{*}{$\begin{array}{l}\text { Actuator } \\
\text { B force } \\
F_{\mathrm{B}}(\mathrm{kN})\end{array}$} & \multirow[b]{2}{*}{$\begin{array}{c}\text { Shear at } \\
\text { connection } \\
F_{\mathrm{c}}(\mathrm{kN})\end{array}$} & \multirow[b]{2}{*}{$\begin{array}{l}\text { Moment at } \\
\text { connection } \\
M_{\mathrm{c}}(\mathrm{kNm})\end{array}$} & \multicolumn{3}{|c|}{ Bearing force on each screw } \\
\hline & & & & & & $\begin{array}{l}\text { Horizontal } \\
\text { force } \\
V_{\mathrm{h}}(\mathrm{kN})\end{array}$ & $\begin{array}{l}\text { Vertical } \\
\text { force } \\
V_{\mathrm{v}}(\mathrm{kN})\end{array}$ & $\begin{array}{c}\text { Total } \\
\text { vectorial } \\
\text { force } V_{\mathrm{b}} \\
(\mathrm{kN})\end{array}$ \\
\hline 1.00 & 0.355 & 38.81 & -11.09 & 27.72 & -0.887 & -7.72 & 13.86 & 15.86 \\
\hline 1.00 & 0.300 & 40.58 & -11.49 & 29.09 & -0.843 & -7.33 & 14.55 & 16.29 \\
\hline 1.00 & 0.414 & 36.22 & -10.32 & 25.90 & -0.804 & -6.99 & 12.95 & 14.72 \\
\hline 1.75 & 0.480 & 36.16 & -9.52 & 26.64 & -0.193 & -1.68 & 13.32 & 13.43 \\
\hline 1.75 & 0.610 & 38.44 & -11.18 & 27.26 & -1.032 & -8.98 & 13.63 & 16.32 \\
\hline 1.75 & 0.683 & 35.16 & -9.72 & 25.43 & -0.553 & -4.81 & 12.72 & 13.60 \\
\hline 2.50 & 0.735 & 26.51 & -6.12 & 20.38 & 0.524 & 4.55 & 10.19 & 11.16 \\
\hline 2.50 & 0.868 & 30.86 & -7.83 & 23.03 & 0.066 & 0.57 & 11.52 & 11.53 \\
\hline 2.50 & 0.898 & 25.06 & -5.79 & 19.27 & 0.494 & 4.29 & 9.63 & 10.55 \\
\hline 2.875 & 0.903 & 16.88 & -3.21 & 13.68 & 0.877 & 7.62 & 6.84 & 10.24 \\
\hline 2.875 & 1.477 & 19.82 & -4.15 & 15.68 & 0.730 & 6.35 & 7.84 & 10.09 \\
\hline 2.875 & 1.072 & 17.49 & -3.50 & 14.00 & 0.771 & 6.70 & 7.00 & 9.69 \\
\hline 3.25 & 4.582 & 6.65 & 0.07 & 6.72 & 1.384 & 12.03 & 3.36 & 12.49 \\
\hline 3.25 & 4.526 & 7.01 & 0.12 & 7.13 & 1.496 & 13.01 & 3.56 & 13.49 \\
\hline 3.25 & 4.486 & 6.08 & 0.32 & 6.41 & 1.468 & 12.77 & 3.20 & 13.16 \\
\hline
\end{tabular}


Table 4: Parameters for the analytical model.

\begin{tabular}{cccc}
\hline Test & $V_{\mathrm{b}}(\mathrm{kN})$ & $d_{\mathrm{b}}(\mathrm{mm})$ & $D(\mathrm{~mm})$ \\
\hline Series 1 & 12.2 & 1.70 & 160 \\
Series 2 & 14.0 & 4.50 & 115 \\
\hline
\end{tabular}

